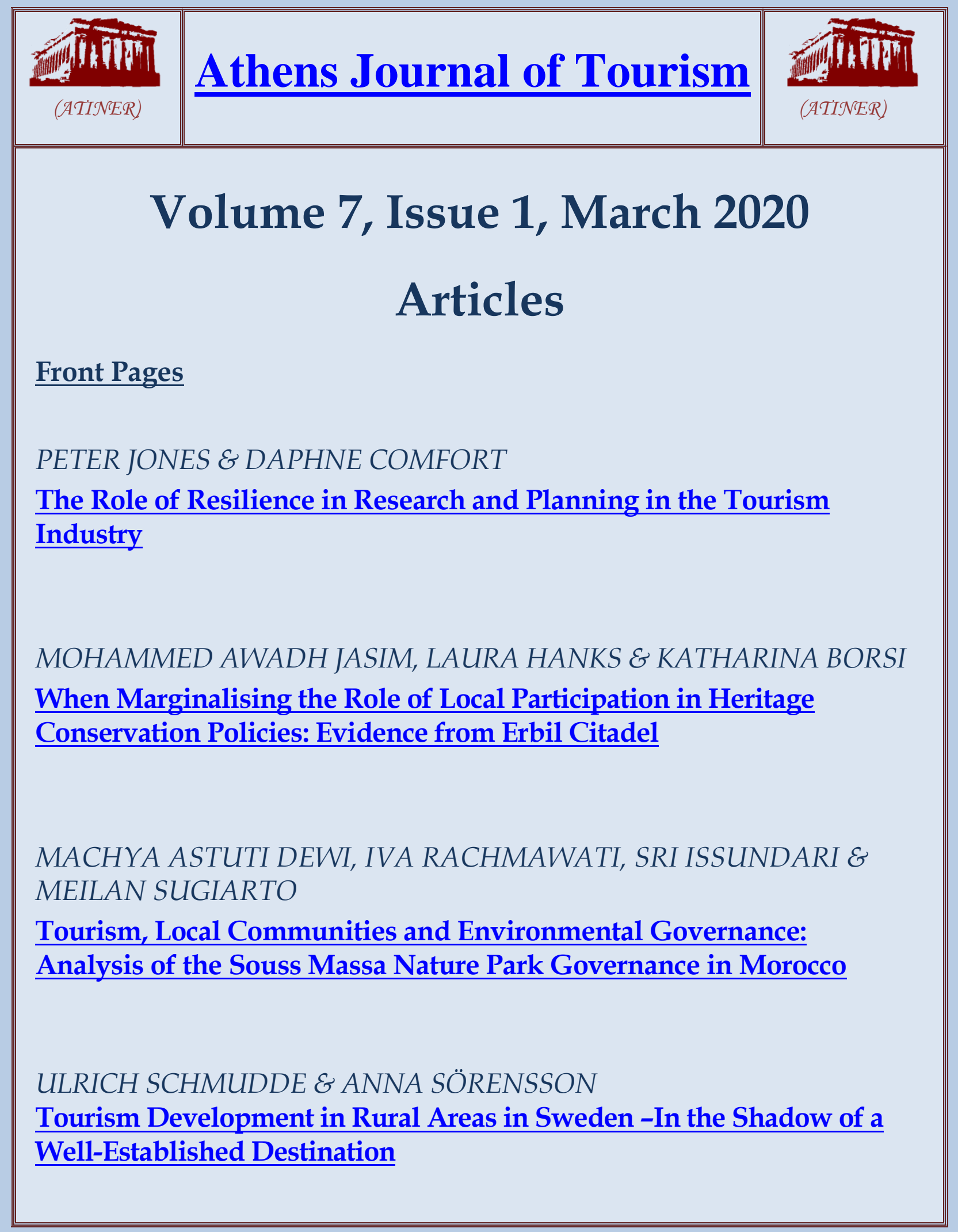




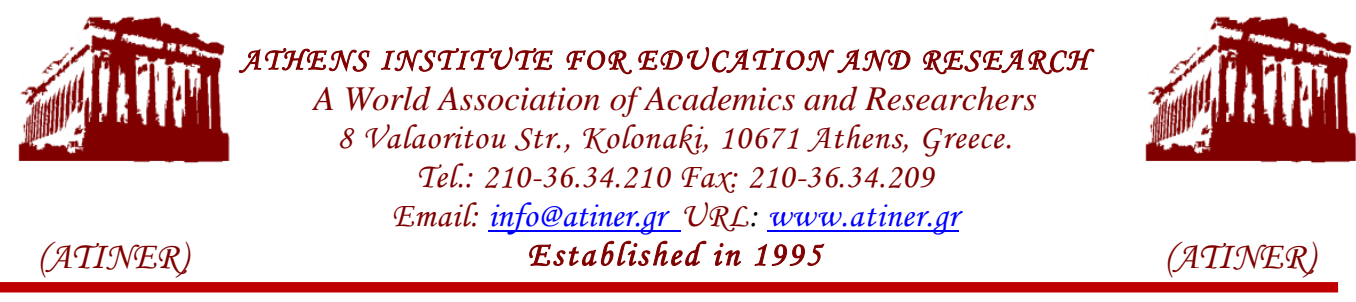

\section{Mission}

ATINER is an Athens-based World Association of Academics and Researchers based in Athens. ATINER is an independent and non-profit Association with a Mission to become a forum where Academics and Researchers from all over the world can meet in Athens, exchange ideas on their research and discuss future developments in their disciplines, as well as engage with professionals from other fields. Athens was chosen because of its long history of academic gatherings, which go back thousands of years to Plato's Academy and Aristotle's Lyceum. Both these historic places are within walking distance from ATINER's downtown offices. Since antiquity, Athens was an open city. In the words of Pericles, Athens"... is open to the world, we never expel a foreigner from learning or seeing". ("Pericles' Funeral Oration", in Thucydides, The History of the Peloponnesian War). It is ATINER's mission to revive the glory of Ancient Athens by inviting the World Academic Community to the city, to learn from each other in an environment of freedom and respect for other people's opinions and beliefs. After all, the free expression of one's opinion formed the basis for the development of democracy, and Athens was its cradle. As it turned out, the Golden Age of Athens was in fact, the Golden Age of the Western Civilization. Education and (Re)searching for the 'truth' are the pillars of any free (democratic) society. This is the reason why Education and Research are the two core words in ATINER's name. 
The Athens Journal of Tourism

ISSN NUMBER: 2241-8148- DOI: 10.30958/ajt

Volume 7, Issue 1, March 2020

Download the Entire Issue (PDF)

Front Pages $\quad$ i-viii

The Role of Resilience in Research and Planning in the 1

Tourism Industry

Peter Jones \& Daphne Comfort

Developing Border Tourism in Sota, Merauke through

Tourism Festival

Mohammed Awadh Jasim, Laura Hanks \& Katharina Borsi

Tourism, Local Communities and Environmental

Governance: Analysis of the Souss Massa Nature Park

Governance in Morocco

Machya Astuti Dewi, Iva Rachmawati, Sri Issundari \& Meilan Sugiarto

Tourism Development in Rural Areas in Sweden -In the Shadow of a Well-Established Destination

Ulrich Schmudde \& Anna Sörensson 


\section{Athens Journal of Tourism Editorial and Reviewers' Board}

Editors

- Dr. Peter Jones, Professor of Management, University of Gloucestershire, U.K.

- Dr. Valia Kasimati, Head, Tourism, Leisure \& Recreation Unit, ATINER \& Researcher, Department of Economic Analysis \& Research, Central Bank of Greece, Greece.

\section{Editorial Board}

- $\quad$ Dr. Francesco Favia, Academic Member, ATINER \& President, Apuliae Open University, Italy.

- Dr. Mary L. Tanke, Distinguished Professor, Chaplin School of Hospitality \& Tourism Management Biscayne Bay Campus, Florida International University, USA.

- Dr. Cláudia Ribeiro de Almeida, Adjunct Professor, University of Algarve, Portugal.

- Dr. Cinthia Rolim de Albuquerque Meneguel, Teacher and Researcher, Federal Institute of Education, Science and Technology of Sao Paolo, Brazil.

- Dr. Kevin Mearns, Professor, Department of Environmental Sciences, UNISA, South Africa.

- Dr. Ige Pirnar, Professor and Member, University Executive Board, Department of Business Administration, Yasar University, Faculty of Economics and Administrative Studies, Turkey.

- $\quad$ Dr. Henry Thompson, Professor Emeritus, Department of Economics, Auburn University, USA.

- $\quad$ Dr. Andrew Yiannakis, Professor, University of New Mexico, USA.

- Dr. Mzobanzi Erasmus Mnguni, Head, Department of Hospitality and Tourism, Durban University of Technology, South Africa.

- $\quad$ Dr. Kathryn Velander, Academic Member, ATINER \& Reader, Edinburgh Napier University, UK.

- Dr. Moustafa Ahmed El-Sayed Ahmed Mekawy, Associate Professor, University of Sadat City, Egypt.

- Dr. Graham Busby, Associate Professor, Faculty of Business, School of Tourism and Hospitality, Plymouth University, UK.

- Dr. Phylis Floyd, Academic Member, ATINER \& Associate Professor, Department of Art, Art History \& Design, Michigan State University, USA.

- $\quad$ Dr. Michael Scantlebury, Academic Member, ATINER \& Associate Professor, Grand Valley State University, USA.

- $\quad$ Dr. Rodanthi Tzanelli, Academic Member, ATINER \& Associate Professor of Cultural Sociology, School of Sociology \& Social Policy, University of Leeds, U.K.

- Dr. Essam Abdel Salam Gouda, Academic Member, ATINER \& Assistant Professor, College of Engineering, Al-Azhar University, Egypt.

- $\quad$ Dr. Tarek Abdelsalam, Assistant Professor, Department of Architecture, University of Modern Sciences and Arts (MSA), Egypt.

- Dr. Aytug Arslan, Assistant Professor, İzmir Katip Çelebi University, Tourism Faculty, Department of Tourist Guidance, Turkey.

- $\quad$ Dr. Sonia Khan, Assistant Professor in Tourism, H.P. University, Shimla, India.

- Dr. Ozlem Karakul, Associate Professor, Faculty of Arts, Selçuk University, Turkey.

- Dr. Per Ake Nilsson, Assistant Professor in Tourism Science, Mid Sweden University, Sweden.

- $\quad$ Dr. Roselyne N. Okech, Assistant Professor, Memorial University of Newfoundland, Canada.

- Dr. Marianna Strzelecka, Assistant Professor, Department of Hospitality and Tourism Management, College of Merchandising, Hospitality and Tourism, University of North Texas, USA.

- Dr. Maria Belen Kraser, Teacher in Seminary Gestion of natural resources and environment, and Didactic of Geography, Universidad Nacional del Sur- UNS, Brazil.

- Dr. Azila Azmi, Senior Lecturer, Faculty of Hotel and Tourism Management, University of Technology MARA (Pulau Pinang), Malaysia.

- $\quad$ Dr. Lois Ann Burgess, Lecturer, School of Management and Marketing, University of Wollongong, Australia.

- Dr. Joseph Mensah-Ansah, Lecturer, GIMPA Business School, Ghana.

- $\quad$ Ms. Suchitra Wagle, Academic Member, ATINER \& PhD and Researcher, Indian Institute of Technology, India.

- Ms. Hatice Ozgul Ozhisar, Academic Member, ATINER \& Ph.D. Candidate, Middle East Technical University, \& Expert, Ministry of Tourism, Turkey.

- Vice President of Publications: Dr Zoe Boutsioli

- General Managing Editor of all ATINER's Publications: Ms. Afrodete Papanikou

- ICT Managing Editor of all ATINER's Publications: Mr. Kostas Spyropoulos

- Managing Editor of this Journal: Ms. Eirini Lentzou (bio) 


\section{President's Message}

All ATINER's publications including its e-journals are open access without any costs (submission, processing, publishing, open access paid by authors, open access paid by readers etc.) and is independent of presentations at any of the many small events (conferences, symposiums, forums, colloquiums, courses, roundtable discussions) organized by ATINER throughout the year and entail significant costs of participating. The intellectual property rights of the submitting papers remain with the author. Before you submit, please make sure your paper meets the basic academic standards, which includes proper English. Some articles will be selected from the numerous papers that have been presented at the various annual international academic conferences organized by the different divisions and units of the Athens Institute for Education and Research. The plethora of papers presented every year will enable the editorial board of each journal to select the best, and in so doing produce a top-quality academic journal. In addition to papers presented, ATINER will encourage the independent submission of papers to be evaluated for publication.

The current issue is the first of the seventh volume of the Athens Journal of Tourism, published by the Tourism, Leisure \& Recreation Unit of ATINER.

Gregory T. Papanikos

President

ATINER 


\section{Athens Institute for Education and Research A World Association of Academics and Researchers}

\section{3 ${ }^{\text {th }}$ Annual International Conference on \\ Mediterranean Studies, 6-9 April 2020, Athens, Greece}

The Center for European \& Mediterranean Affairs organizes the $13^{\text {th }}$ Annual International Conference on Mediterranean Studies, 6-9 April 2020, Athens, Greece sponsored by the Athens Journal of Mediterranean Studies. The aim of the conference is to bring together academics and researchers from all areas of Mediterranean Studies, such as history, arts, archaeology, philosophy, culture, sociology, politics, international relations, economics, business, sports, environment and ecology, etc.You may participate as stream leader, presenter of one paper, chair a session or observer. Please submit a proposal using the form available (https://www.atiner.gr/2020/FORM-MDT.doc).

\section{Academic Members Responsible for the Conference}

- Dr. Gregory T. Papanikos, President, ATINER \& Honorary Professor, University of Stirling, U.K.

- Dr. Steven Oberhelman, Professor of Classics, Holder of the George Sumey Jr Endowed Professorship of Liberal Arts, and Associate Dean, Texas A\&M University, USA, Vice President of International Programs, ATINER and Editor of the Athens Journal of History.

- Dr. Nicholas Pappas, Vice President of Academic Membership, ATINER \& Professor of History, Sam Houston University, USA.

- Dr. David Philip Wick, Director, Arts, Humanities and Education Division, ATINER \& Professor of History, Gordon College, USA.

- Dr. Yannis Stivachtis, Director, Center for European \& Mediterranean Affairs and Associate Professor, Jean Monnet Chair \& Director of International Studies Program, Virginia Tech - Virginia Polytechnic Institute \& State Universitv, USA.

- Abstract Submission: 24 February 2019

- Acceptance of Abstract: 4 Weeks after Submission

- Submission of Paper: 9 March 2020 


\section{Conference Fees}

Conference fees vary from $400 €$ to $2000 €$

Details can be found at: https://www.atiner.gr/2019fees

\section{Social and Educational Program}

The Social Program Emphasizes the Educational Aspect of the Academic Meetings of Atiner.

- Greek Night Entertainment (This is the official dinner of the conference)

- Athens Sightseeing: Old and New-An Educational Urban Walk

- Social Dinner

- Mycenae Visit

- Exploration of the Aegean Islands

- Delphi Visit

- Ancient Corinth and Cape Sounion

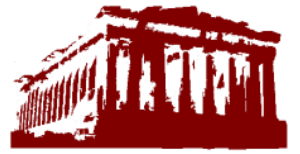

\section{Athens Institute for Education and Research}

A World Association of Academics and Researchers

\section{$1^{\text {th }}$ Annual International Conference on Tourism \\ 8-11 June 2020, Athens, Greece}

The Tourism, Leisure \& Recreation Unit of ATINER organizes its 16 $^{\text {th }}$ Annual International Conference on Tourism, 8-11 June 2020, Athens, Greece sponsored by the Athens Journal of Tourism. The aim of the conference is to bring together academics and researchers from all areas of Tourism. You may participate as stream leader, presenter of one paper, chair a session or observer. Please submit a proposal using the form available (https:// www.atiner.gr/2020/FORM-TOU.doc).

- Abstract Submission: 27 April 2020

- Acceptance of Abstract: 4 Weeks after Submission

- Submission of Paper: 11 May 2020

\section{Academic Member Responsible for the Conference}

- Dr. Valia Kasimati, Head, Tourism, Leisure \& Recreation Unit, ATINER \& Researcher, Department of Economic Analysis \& Research, Central Bank of Greece, Greece.

- Dr. Peter Jones, Co-Editor, Athens Journal of Tourism \& Professor of Management, University of Gloucestershire, UK.

\section{Social and Educational Program}

The Social Program Emphasizes the Educational Aspect of the Academic Meetings of Atiner.

- Greek Night Entertainment (This is the official dinner of the conference)

- Athens Sightseeing: Old and New-An Educational Urban Walk

- Social Dinner

- Mycenae Visit

- Exploration of the Aegean Islands 


\section{Conference Fees}

Conference fees vary from $400 €$ to $2000 €$

Details can be found at: https:// www.atiner.gr/2019fees 




\title{
The Role of Resilience in Research and Planning in the Tourism Industry
}

\author{
By Peter Jones * \& Daphne Comfort ${ }^{\dagger}$
}

\begin{abstract}
The concept of resilience is attracting increasing attention across a wide range of academic disciplines and business sectors. While academic researchers have increasingly employed the concept to inform their work on sustainability, there is also growing interest in a wider conceptualisation of resilience as the focus for tourism planning. With these thoughts in mind, this exploratory paper reviews how the concept of resilience is both illuminating academic research on sustainability and guiding the development of new planning strategies, within the tourist industry and offers some wider reflections on the use of the concept within the industry.
\end{abstract}

Keywords: Resilience, Tourism, Research, Planning, Climate Change, Disruptive Technologies.

\section{Introduction}

'Resilience has emerged as a hot topic in the tourism and hospitality literature' (Prayag et al. 2018).

The concept of resilience is attracting increasing attention across a wide range of academic disciplines and business sectors (Jones and Comfort 2018; Sarda and Pogutz 2018). On the one hand, academic researchers have increasingly employed the concept to inform their work on sustainability, while on the other hand, there is also growing interest in a wider conceptualisation of resilience as the focus for business planning. Within the tourism industry uncertainties about the growing impact of climate change, the increasing incidence of extreme weather events, the contributions of air traffic and cruising to greenhouse gas emissions and air and water pollution, the environmental and social impacts of tourism in fragile environments and traditional and remote communities, and the proliferation of disruptive technologies, are posing increasingly difficult challenges. These challenges are bringing the concept of resilience into seemingly ever-sharper focus within the industry. Luthe and Wyss (2014), for example, suggested 'resilience as a concept has much explanatory power that requires more attention in tourism research.' With these thoughts in mind, this exploratory paper reviews how the concept of resilience is both illuminating academic research on sustainability and

\footnotetext{
*Professor of Management, University of Gloucestershire, UK.

${ }^{\dagger}$ Researcher, University of Gloucestershire, UK.
} 
guiding the development of new planning strategies for the tourist industry and offers some wider reflections on the use of the concept within the industry.

\section{Resilience}

In everyday language, resilience is seen as the ability to withstand or to bounce back from adversity and disruption. In the academic and business world, a number of meanings have been identified and while Sharifi and Yamagata (2014) suggested that 'despite the abundance of research on resilience there is still no single, universally accepted definition for it', Fabry and Zeghui (2019) argued 'there are competing definitions of resilience.' Certainly, a number of origins and meanings are claimed for resilience. Hassler and Kohler (2014), for example, claimed that 'resilience as a design principle, was an implicit part of construction knowledge before the nineteenth century' and Sharifi and Yamagata (2014) suggested that 'the concept of resilience has traditionally been used in physics and psychology.' Davoudi (2012 et al.) acknowledged that 'resilience was first used by physical scientists' and argued that in the 1960's 'resilience entered the field of ecology.' MacKinnon and Derickson (2013) suggested that 'the concept of resilience has migrated from the natural and physical sciences to the social sciences and public policy, as the identification of global threats such as economic crisis, climate change and international terrorism has focused attention on the responsive capacities of places and social systems.' Adger (2000) defined social resilience as 'the ability of groups or communities to cope with external stresses and disturbances as a result of social, political and environmental change.' More generally, work across the disciplines is concerned with the ability of systems to withstand and recover from major disruptions.

There is also growing recognition of the importance of resilience within the corporate world. PricewaterhouseCoopers (2017a), for example, emphasised their belief that 'enterprise resilience is the most important capability in business today.' Here enterprise resilience is defined as 'an organisation's capacity to anticipate and react to change, not only to survive, but also to evolve' (PricewaterhouseCoopers 2017b.) At the same time, there is growing interest in the creation of resilient business strategies. In introducing 'resilient business strategies', the BSR (2018), have argued 'rather than integrate sustainability into company strategy, we believe companies need to create resilient business strategies.' Such strategies are 'based on an understanding that rapidly-shifting external context - our changing demographics, disruptive technologies, economic dislocation and natural resource scarcity are not only sustainability issues but also business issues (BSR 2018).

More specifically within the tourism industry, Cheer and Lew (2017) claimed 'a paradigmatic shift is taking place in the long-term planning of tourism development, in which the prevailing focus on sustainability is being enhanced with the practical application of resilience planning.' The European Futures Tourism Institute (2019), for example, has claimed that the leisure and tourism industry is continuously in motion', that changes include 'changing lifestyles and consumer behaviour, new technologies such as virtual reality, terrorism, climate 
adaptation, the importance of sustainability, the call for new business models and forms of value creation. As such 'for the sector it is essential to react and anticipate to these developments. In other words, to be resilient' (European Futures Tourism Institute 2018). Espiner et al. (2017) suggested that while 'sustainability has endured as an important concept for tourism scholars'..... more recently resilience has generated appeal in the academic tourism literature as a term that might capture core aspects of sustainability.' In their review of 'The Global Conference on Jobs and Inclusive Growth:Partnerships for Sustainable Tourism' held in Jamaica in 2017, Twinning-Ward et al. (2017) argued 'the key word for the conference was resilience: not only how to build back better, but also how to build resilience into the everyday management of tourism, how to be better prepared, how to manage a crisis, and how to ensure greater shared economic and social benefits from tourism in the region. '

While the paper is not focused around explicit research questions, the aim is to review how the concept of resilience is illuminating academic research on sustainability and guiding the development of new planning strategies for the tourism industry. To this end the authors undertook two Internet searches. In looking to review the academic research on resilience in tourism, the authors used Google Scholar with the key phrase 'resilience and tourism' and for the development of new planning strategies for tourism, the key phrase 'planning for resilience in tourism' was entered into Google. The papers and reports generated by these two searches provided the material from which the authors selected the material which forms the main body of this paper. The authors are aware that their approach has a number of limitations, but in selecting material, they have looked to reflect the diversity and variety of research and practitioner work on resilience in tourism, and they feel it is appropriate given the exploratory nature of the paper.

\section{Research into Resilience within the Tourism Industry}

The concept of resilience has attracted growing attention from researchers exploring sustainability within the tourism industry and while this work is still in its infancy several, often interlinked themes, which offer a loose sense of structure, for this emerging field, can be identified. Namely,

- conceptual and theoretical frameworks;

- destination resilience;

- sensitive environments;

- community resilience;

- climate change;

- disaster resilience in the hotel sector;

- leadership.

A number of examples provide some flavour of the range and nature of this work. 
Basurto-Cadeno and Pennington-Gray (2018), for example, offered ' $a$ conceptual framework of destination resilience for developing indicators that tourist destinations can use to measure crisis resilience for their tourism industry' which is intended as a starting point for a wider discussion of factors that contribute to destination resilience.' Calgaro et al. (2014) adopted a 'dynamic coupled human-environment system perspective' to develop a framework to assess the vulnerability and resilience of tourist destinations. Lew (2013) outlined a matrix model, based around both the scale and the rate of change within tourism, which presented four contexts, each with distinct resilience issues, and which, in turn, were associated with specific responses, including facilities and services maintenance programmes, training and welfare support systems. Halliday (2018), looked to 'present intersecting theories between destination resilience and sustainable tourism' and proposed a 'heuristic model to stimulate theories of destination resilience within the context of sustainable tourism.'

Fabry and Zeghui (2019) identified resilience 'as an emerging concept in destination management' and claimed 'resilience is not a status but a frame of mind.' Basurto-Cadeno and Pennington-Gray (2018) claimed that 'destinations around the world are adopting a resilience framework to deal with the increasing frequency and intensity of disasters affecting the tourism industry' and proposed a scalable resilience model, which is applicable to diverse types of risks and different size destinations. In looking to evaluate tourism resilience in Grenada, Filimonau and DeCoteau (2019) suggested that while local tourism stakeholders are aware of the potential damage that natural disasters can have on destinations, they fail to develop effective measures to build destination wide and organizational resilience. More generally, Butler (2018) argued for a 'more critical review of so-called sustainable forms of tourism and a focus to shift towards increasing the resilience of destinations, particularly those in sensitive areas, in order to shield them from the effects of inappropriate or excessive tourism development.'

Biggs (2011) examined the 'perceived resilience of reef tourism enterprises on Australia's Great Barrier Reef to large disturbances or shocks.' His findings revealed that where owners and managers are themselves 'active in reef tourism as a lifestyle choice' this enhances enterprise resilience. Further Biggs (2011) argued that financial and marketing support are the most important actions governments can take to support enterprises in the face of a large shock.' In a similar vein, Biggs et al. (2011) explored the resilience of both formal and informal tourism enterprises in a study of reef tourism in Phuket in Thailand. Recognising that coral reef tourism was particularly vulnerable to both extreme natural events and economic and political shocks, Biggs et al. (2011) stressed that enterprise resilience was central to sustainable tourism management and recommended that management policies designed to support reef tourism should encourage enterprise flexibility and facilitate cost cutting measures during times of crisis.

Orchiston (2013) looked to examine tourism disaster planning in a high seismic risk area of New Zealand's Southern Alps, and she drew on the business resilience literature to outline an alternative approach to disaster planning for small communities reliant on tourism. In a study of the remote tourist townships of 
Franz Josef and Fox Glacier in New Zealand's "Glacier Country" Espiner and Becken (2014), used the concepts of resilience and vulnerability to examine how change and response have shaped the community, conservation and tourism. Further Espiner and Becken (2014) concluded vulnerability and resilience are discrete but highly compatible concepts, offering much to the analysis of protected area tourism facing global change. Lambert et al. (2010) presented a framework for evaluating the resilience of whale watching tourism to changes in the occurrence of species and suggested that their finding could offer ' $a$ means by which resilience to global climate change effects on cetacean species (whales, dolphins and porpoises) could potentially be provided.'

Though Lew (2013), suggested that 'tourism scholars had been somewhat slow to adopt recent conceptual ideas related to community resilience' this is certainly an emerging area of academic endeavour. Five years later, Cheer and Lew (2018) argued that 'for many tourism-centred communities around the globe, the process of adapting to and dealing productively with the transformations to social, political and economic contexts that influence and underline their tourism and wider prospects is an ongoing challenge.' Lew (2013) outlined a matrix model, based around both the scale and the rate of change within tourism, which presented four contexts, each with distinct resilience issues, and which, in turn, were associated with specific responses, including facilities and services maintenance programmes, training and welfare support systems.

Bec et al. (2016) suggested that some of the academic work on community resilience had focused on the tourism system's ability to respond to short term problems and looked to identify core concepts of community resilience to develop a framework to explore community resilience to long term tourism decline. Amir et al. (2015) explored the resilience of communities to rural tourism development in Malaysia and Powell et al. (2017) explored how community resilience could assist sustainable tourism development in the Dong Van Geopark in Vietnam. Sydnor-Bousso et al. (2011) discussed the impact of natural disasters on jobs in the hospitality and tourism industry, looked to model job resilience after such disasters, and suggested that changes in jobs within the industry are a function of community resilience.

Resilience to the impacts of climate change on tourism is attracting increasing attention. In general terms, Dogru et al. (2019) looked to examine the extent to which resilience to climate change affects tourism and argued that mitigation policies should be prioritized at a global scale. In assessing the implications of the 2013-2014 report of the Intergovernmental Panel on Climate Change, Scott et al. (2016), claimed that 'a lack of understanding of the integrated impacts of climate change and the effectiveness of adaptation strategies potentially hinders the development of resilient tourism operations and destinations.' More specifically, Wyss et al. (214) examined the role of cooperation in building resilience to climate change in alpine tourism networks. Here the principal focus of the paper was to devise 'comparable resilience metrics, based on social network analysis, to assess the structural strengths and weaknesses of a geographically delimited tourism system in the face of climate change' (Wyss et al. 2104). 
A number of studies have focused on of disaster resilience in the hotel sector. Dobie et al. (2018), for example, suggested 'the hotel and lodging industry will be especially crucial in community response and recovery, as many of these properties are located in coastal regions that are disaster prone, are a crucial component of tourist destination' economies, and often act as hubs for resilience during disasters.' The authors concluded that while many properties are engaging in Corporate Social Responsibility activities during disaster relief, 'corporate management systems have room for maturation and growth to support the resilience of their community.' Brown et al. (2017) explored how disaster and resilience are framed in the hotel sector. This review highlighted the importance of prioritising resilience building in the hotel sector but suggested that improvements were required in the sector's disaster preparedness and concluded by recommending that all stakeholders within the sector should be actively involved in the improvement process.

Researchers have also explored the role and importance of resilience leadership within tourism. Haver et al. (2014), for example, examined how general managers within the industry regulated their emotions in the face of complex and demanding leadership duties and responsibilities. The results of this research revealed that 'experienced general managers have to develop resilience through extensive experience and wise emotional regulation' (Haver et al. 2014). In a study of work engagement and frontline employees' satisfaction within the hotel industry, Karatepe and Karadas (2015) revealed that resilience was one of the best indicators of psychological capital, which inter alia, was seen to be important in managing service encounters. In looking to measure the resilience of hospitality businesses in Auckland, New Zealand, Tibay et al. (2018) concluded that leadership and management, was a key resilience attribute.

\section{Resilience Planning Strategies in the Tourism Industry}

The concept of resilience is increasingly being employed to illuminate academic research on sustainability in the tourism industry, but there is also emerging interest in developing wider resilient tourism plans. Resilient tourism plans are being developed in several areas, including the Dominica, Samoa, Nepal, Tanzania, Japan and arguably most comprehensively in Queensland, Australia. Such plans address a range of challenges for the tourism industry, including natural hazards, natural resource scarcity, and changing demographics, but resilience to climate change is a dominant theme. While the plans outlined below do not look to provide a comprehensive picture of resilience planning in the tourism industry, they offer some valuable insights into some of the elements in the resilience planning process.

Increasing resilience to climate change is an important element in the 'Dominica National Land Use Policy' (Ministry of Environment, Natural Resources Physical Planning and Fisheries 2014), which stresses the importance of planning for 'the impacts of climate change through investment in resilient infrastructure and early warning systems.' More specifically, the focus is on 
'allowing the natural environment's own systems to effectively respond to hazard impacts through integrated watershed and coastal zone management' on 'directing development into safe areas' and on 'minimising the effects of human activities that put property and public safety at risk' (Ministry of Environment, Natural Resources Physical Planning and Fisheries 2014). In 'Promoting Private Sector Engagement in Climate Resilient Tourism', the Government of Nepal Ministry of Culture, Tourism and Civil Aviation (2018) recognised that the country's 'tourism resources are highly vulnerable to climate change.' In looking to promote private sector engagement in the tourism industry, the focus is on encouraging investment for climate resilience in supply chain management, encouraging the diversification of the country's tourism products and more timely climate information management.

The aim of Samoa's 'Enhancing the Resilience of Tourism Reliant Communities to Climate Change Risks' (Samoan Tourism Authority 2017) project is to increase the resilience of the tourism sector of Samoa 'through mainstreaming climate risks into tourism related policy processes and adaptation actions in coastal communities and tourism operators.' The various components within the project are designed to address climate change through an integrated approach which looks to combine policy and institutional strengthening to support public/private partnerships and encourages the engagement of local communities with adaptation measures, in important community based tourism areas. Management plans integrating climate risks have been developed in four tourism development areas, a technical guide has been developed on climate resilient beach tourism management practices, adaptation actions have been implemented in several villages and community owned beach tourism operations, and coastal tourism operators are connected to a climate early warning system.

Resilience plans are also being developed to address concerns about the impact of the growth in tourism on natural resources and on the natural environment also underpin resilience plans. The Resilient Natural Resource Management for Tourism and Growth Project for Tanzania, launched in 2018, looks to improve management of natural resources and tourism assets in priority areas of Southern Tanzania and to increase access to alternative livelihood activities for targeted communities' (The World Bank 2017). The project has four components namely: to strengthen the management and improve the infrastructure in protected areas; to strengthen landscape management and infrastructure investments in and upstream of the Ruaha National Park; to strengthen alternative livelihoods for targeted communities in proximity to the protected areas; and to put measures in place for quality assurance and control and monitoring and evaluation, to ensure coordinated and timely project execution. In addressing landscape management, for example, the focus is on augmenting the dry season flow of the area's rivers, conservation working in a number of river basins, and consensus building for land and water management

Following the major earthquake and tsunami in East Japan in 2011 a resilience plan was launched for the tourist industry by the Prefecture Government in Okinawa (JTB Tourism Research and Consulting Company 2017).This plan included a number of activities including a series of seminars designed to educate 
tourism stakeholders, the development of a series of crisis management manuals, designed for local destinations and service providers, the creation of evacuation maps for major tourist areas and the development of an emergency information delivery service for tourism stakeholders and visitors. More generally, the plan has raised awareness amongst local tourism stakeholders and citizens of the potential risks that might impact upon the tourist sector, local hotels have become better prepared for disaster risks and a close partnership has been built between the public and private sector to address the disasters that can impact upon tourism.

Perhaps the most comprehensive approach to resilience planning within the tourism industry has been developed in Queensland, Australia. In 2018 the launch of the 'Queensland Climate Adaptation Strategy' (Queensland Tourist Industry Council 2018a) was billed as 'the world's first industry-led climate change response plan' (Queensland Tourism Industry Council 2018b). The plan explicitly recognised that 'climate change is both a risk and an opportunity' for 'tourism businesses' and that 'the increasing costs of extreme weather events, changes to natural resources, and the transition to a decarbonised global economy are all highly relevant to tourism' (Queensland Tourist Industry Council 2018a).

More specifically, the plan sets out a vision for the future, structured around a number of building blocks, namely:

$>$ 'resilient businesses, destinations and communities';

$>$ 'stewardship and education for healthy natural assets';

$>$ a 'green tourism industry leading the way towards carbon neutrality';

$>$ a 'diversified product for quality visitor experience';

$>$ 'sustainable branding and marketing'; and

$>$ a 'tourism industry working together with government and communities.' (Queensland Tourist Industry Council 2018a)

The economic, environmental and social rationale for the plan embraces a wide range of issues. Economically, for example, there is the recognition that climate risks impose a range of costs on businesses across the tourism industry and that a failure to invest in a climate resilient and low carbon infrastructure carries a potentially major risk for companies and investors. At the same time there is also a recognition that the need to comply with new legislation and to disclose carbon emissions is becoming an increasingly mainstream business commitment. Environmentally, the plan emphasises not only that tourism in Queensland depends on the environment but also that it needs advocates to protect it. On the social side the plan recognises the importance of employment within the tourist industry and that tourism is deeply interwoven with communities who depend on it in a variety of ways. Ultimately, the plan argued that 'Queensland's competitiveness in terms of attractiveness' .... 'is an important collective reason for addressing climate change' (Queensland Tourist Industry Council 2018a).

More specifically, the plan sets out a number of tools available to tourism businesses and decision makers to help them to respond to climate change. These tools cover general climate information, reduction in carbon emissions, risk assessment and resilience building, adaptation planning, coastal inundation and 
rises in sea level, flood management, extreme weather events and specific risks to businesses and infrastructure. In focusing on tools to reduce carbon emissions, for example, the plan drew attention to the potential for the tourist industry to increase energy efficiency and to design and to develop more energy efficient buildings and tourist attractions.

The plan also addressed a wide range of other climate hazards and risks including changes to the Great Barrier Reef, tropical cyclone intensity and changes in the distribution of wildlife and diseases. In addressing wildlife and diseases, for example, the report suggested that with increases in temperatures, rainfall and humidity, mosquito borne diseases, such as malaria and dengue fever, currently confined to northern Queensland, could spread south and become more difficult to control. There are also concerns that a warmer climate and changes in rainfall patterns could increase the range of and prevalence of food and water borne diseases with major implications for the public health of both tourists and residents. At the same time, changes in the climate may increase the southern spread of potentially dangerous animal species. The plan suggested that all these potential changes may affect the health and safety of tourists, which may, in turn, potentially compromise their comfort and increase their costs and more generally may cause reputational damage.

The emergence and proliferation of a range of disruptive technologies provides a range of major challenges for the tourism industry and in the face of such challenges, the Queensland Government has emphasised the importance of building the resilience and competitiveness of the industry. The Tourism Disruptive Technologies Project launched by the Queensland Tourism Industry Council (2019a) recognised the 'shift towards the use of digital technology by consumers in the conceptualisation, planning and sharing of their travel experiences.' More specifically, the aim of the project is 'to develop a digital workforce and training plan for the Queensland tourism industry that identifies gaps in digital uptake among industry members, the impact and implication of new technology on the industry, and the opportunities that technology presents to enhance destination experiences' (Queensland Tourism Industry Council 2019b).

\section{Reflective Conclusions}

The use of the concept of resilience in both academic research on tourism and in the development of planning strategies for the tourism industry, is certainly attracting increasing attention, but three wider sets of issues merit discussion and reflection. In part, the following discussion reflects general issues about the use of the concept of resilience and in part, it links these issues to specific challenges within the tourism industry. Firstly, then measuring resilience is a thorny issue and the measurement process faces a number of conceptual and methodological challenges. Conceptually, different definitions of resilience do not make measurement an easy task and given that resilience is generally seen as being both time and place specific, then it is difficult to establish generic measures which facilitate comparisons over time and space. Methodologically the collection of 
reliable and meaningful data, particularly in environments and communities, which have suffered shocks, crises and threats, may prove difficult and here companies, organisations and researchers may resort to using available and/or surrogate data rather than looking to collect original data in the field.

Orchiston and Espiner (2018) argued while the empirical measurement of resilience is in its infancy within the academic discourse, there is increasing pressure from tourism practitioners and funding agencies to improve our understanding of resilience metrics and the ways in which resilience measures can be applied though adaptive business management practices to improve the social and environmental outcomes of tourism operations.' More generally, a number of resilient measurement frameworks have been developed. Schipper and Langston (2015), for example, listed 17 such frameworks but variations in their aims, scale and method of analysis make comparisons difficult. Within the tourism industry, Cox (2016), working for the National Estuarine Research Reserve System Science Collaborative, developed the 'Tourism Resilience Index' as a self-assessment tool for tourism industry leaders and businesses. The index includes six elements namely: business operations and plans; disaster preparedness and planning; marketing; workforce; federal, state and local resources; and resource access and knowledge. The items within each of these elements are scored on a numerical scale and this scoring system is a subjective self-assessment process, and this makes more widespread comparisons difficult.

Secondly, there are a set of issues around distributional equity and power. Matin et al. (2018), for example, have suggested that the apparent failure of resilience to attend to the distributive and power dimensions of environmental and development problems is a serious limitation of the concept for analysis and practice.' Meerow and Newell (2016), argued that the 'underlying politics of resilience have been ignored' and have stressed the importance of questioning what they describe as 'the five w's of urban resilience' namely resilience for whom, of what, when, where and why. In addressing the question of resilience for whom, for example, Vale (2013) argued that the significance of resilience depends on whose resilience is being described.' Further Vale (2013) suggested that many governments and corporations, for example, may seek to claim the term, but asked 'how do they decide whose resilience to care about?' and 'whose resilience is omitted in the process?' In outlining the importance of the 'when' question, Meerow and Newell (2016) questioned whether the primary goal is to build resistance to short term disruptions (e.g. hurricanes) or long term stress (e.g. precipitation changes caused by climatic change).' More generally Matin et al. (2018) argue that 'as resilience becomes more prevalent in policy and practice, attention to the demands of equitable resilience becomes ever more pressing.'

In addressing power, MacKinnon and Derickson (2013) argued that the concept of resilience 'is conservative when applied to the social sphere' and that, as such, it 'privileges established social structures, which are often shaped by unequal power relations.' Arguably more contentiously, some critics have argued that popular conceptions of resilience privileges the capitalist mode of production. Martin and Sunley (2014), for example, argued that the concept of resilience is easily captured by neoliberal ideology, to prioritise the status quo, and the 
importance of self-reliance, flexibility and the role of self-correcting market adjustments.' More pointedly, MacKinnon and Derickson (2013) concluded 'resilience thinking has become implicated within the hegemonic modes of thought that support global capitalism.'

In focusing on 'the Sphere of Tourism Resilience' in Sri Lanka, Cochrane (2015) claimed that it is in the interests of individual shareholders to grab as many of the benefits as possible.' In a similar vein, Zellmer and Gunderson's (2008) comparative analysis of ecological restoration in Glen Canyon and the Everglades in the US, revealed that 'resilience may not always be a good thing, particularly when it exhibits itself as entrenched stakeholder interests or institutions that do not embrace change.' At the corporate level, many companies, will understandably, focus primarily on their own, often short-term interests. In its response to the impact extreme weather events were having on its business the Thomas Cook Group (2018) outlined its approach to enhancing resilience which centred on 'operating more efficiently and reducing our impact on the environment and our demand for natural resources.'

Thirdly, there are issues about resilience and economic growth and the continuing demands such growth makes on the planet's finite natural resources. The Queensland Tourist Industry Council's (2018b) Climate Adaptation Strategy, for example, neatly captured this dilemma in arguing that 'one critical challenge for tourism is how to reconcile growth with effective climate responses, in particular absolute reductions in carbon emissions' and that ultimately 'the transition requires change by everyone.' At the same time, Cheer and Lew (2018) suggested 'resilience thinking is also prone to criticisms over its hidden links to the neoliberal ideals of development' and that 'critics contend that it gives licence to increase the development exploitation of natural and human resources over concerns for conservation and resource restoration.' Arguably more positively, Cheer and Lew (2018) also argued that 'embracing resilience thinking for tourism development might offer policy, planning and practice a more workable framework that recognises the certainty of changeability, and acknowledges the need for adaptation, rather than giving a disproportionate focus to mitigation and cessation. Further, Cheer and Law (2018) concluded 'this is a more practicable approach to the planning and management of tourism's continual global growth and global reach.'

More radically, Amsler (2019) argued that 'there is a blind spot in analyses that uphold the sustainability of globalized capitalism' and that mainstream thinking, learning and policy effectively help societies to 'become resilient within harmful environments that are conceived as inevitable' rather than to 'generate possibilities for fundamentally other ways of organizing life.' This reinforces Amsler's (2009) earlier invitation 'to explore the complex processes through which competing visions of just futures are produced, resisted and realized.' Such thinking is clearly linked to the notion that resilience has become implicated in supporting global capitalism, outlined earlier, but such approaches may seem both unfamiliar and challenging to many tourism scholars and are unlikely to find any favour whatsoever within the tourism industry. 


\section{References}

Adger, W. N. (2000) Social and Ecological Resilience: Are they related. Progress in Human Geography 24 (3): 347-364

Amir, A.F., Ghapar, A. A., Jamal, S.A. Ahmad, K.N. (2015) Sustainable tourism development: A study on community resilience for rural tourism in Malaysia. Retrieved from https://pdfs.semanticscholar.org/8627/02651299fa124154b3c1b89d dafd47b1c436.pdf [Accessed 10 April 2018]

Amsler, S. S. (2009), Embracing the Politics of Ambiguity: Towards a Normative Theory of Sustainability. Capitalism, Nature and Socialism 20 (2): 111-125.

Amsler, S. S. (2019) Gesturing towards radical futurity in education for alternative futures. Sustainability Science 14 (4): 925-930

Basurto-Cadeno, E. M. and Pennington-Gray, L (2018) An Applied Destination Resilience Model. Tourism Review International 22, (3/4) 293-302

Bec, A., McLennan, C-L. and Moyle, B.D. (2016), Community resilience to long term tourism decline and rejuvenation: a literature review and conceptual model. Current Issues in Tourism 19 (5): 431-457

Biggs, D. (2011), Understanding Resilience in a Vulnerable Industry: the Case of Reef Tourism in Australia. Retrieved from https://www.ecologyandsociety.org/vol16/iss1/ art30/ [Accessed 30 April 2018]

Biggs, D., Hall, C. M. and Stoecki, N. (2012), The resilience of formal and informal tourism enterprises to disasters: reef tourism in Phuket, Thailand. Journal of Sustainable Tourism, 20 (5) 645-665

BSR (2018) Strategy and Value Creation. Retrieved from https://www.bsr.org/repor ts/BSR_Redefining_Sustainable_Business_Act.pdf (Accessed 10 July 2019)

Brown, N.A., Rovins, J.E., Feldmann-Jensen, S. and Orchiston, C. (2017), Exploring disaster resilience within the hotel sector: A systematic review of literature. International Journal of Disaster Risk Reduction 22: 362-370

Butler, R. (2018) Sustainable Tourism in Sensitive Environments: A Wolf in Sheep's Clothing. Sustainability. Retrieved from https://strathprints.strath.ac.uk/64442/1/But ler_Sustainability_2018_Sustainable_tourism_in_sensitive_environments.pdf [Accessed 9 July 2019]

Calgaro, E., Lloyd, K., \& Dominey-Howes, D. (2014). From vulnerability to transformation: A framework for assessing the vulnerability and resilience of tourism destinations. Journal of Sustainable Tourism 22 (3) 341-360.

Cochrane, J. (2015) The Sphere of Tourism Resilience. Tourism Recreation Research 35 (2): $173-185$

Cox, A. (2016) Tourism Resilience Index: A business elf assessment. Retrieved from https://www.wellsreserve.org/writable/files/archive/ctp/tourism_resilience_index_wel lsreserve_copy1.pdf [Accessed 22 July 2019]

Cheer, J. M. and Lew, A. (2017) Tourism, Resilience and Sustainability; Adapting to Social, Political and Economic Change. London: Routledge

Cheer, J.M. and Lew, A. (2018) Sustainable tourism development: Towards resilience in tourism. Retrieved from https://www.researchgate.net/profile/Joseph_Cheer/publica tion/315455898_Sustainable_tourism_development_Towards_resilience_in_tourism/ links/58d0ad7ba6fdcc344b0c130d/Sustainable-tourism-development-Towardsresilience-in-tourism.pdf [Accessed 26 July 2019]

Davoudi, S., Shaw, K., Haider, L.J., Quinlan, A. E., Peterson, G. D., Wilkinson, C., Funfgeld, H., McEvoy, D., and Porter, L. (2012) 'Resilience: A Bridging Concept or a Dead End? Reframing Resilience: challenges for Planning Theory and Practice 
Interacting Traps: Resilience Assessment of a Pasture Management System in Norther Afghanistan Urban Resilience: What does it mean in Planning Practice? Resilience as a Useful Concept for Climate Change Adaptation? The Politics of Resilience in Planning: A Cautionary Note Planning' Theory and Practice' 13 (2): 299-233

Dobie, S., Schneider, J., Kosgin, M. and Lagiewski, R. (2018) Hotels as Critical Hubs for Destination Disaster Resilience: An Analysis of Hotel Corporations CSR Activities Supporting Disaster Relief and Resilience. Infrastructures 3 (4) Retrieved from https://www.mdpi.com/2412-3811/3/4/46/htm [Accessed 10 July 2019]

Dogru, T., Marchio, E.A., Bulut, U. and Suess, C. (2019) Climate change: vulnerability and resilience of tourism and the entire economy. Tourism Management 72 (2019): 292-305

Espiner, S. and Becken, S. (2014), Tourist towns on the edge: conceptualising vulnerability and resilience in a protected area tourism system. Journal of Sustainable Tourism, 22 (4): 646-665

Espiner, S., Orchison, C. and Higham, J. (2017) Resilience and sustainability: a complementary relationship? Towards a practical conceptual model for the sustainability-resilience nexus in tourism. Journal of Sustainable Tourism 26 (10): 1385-14008)

European Futures Tourism Institute (2019) EFTI's future: building resilience in tourism. Retrieved from https://www.etfi.nl/en/blog/etfi\%E2\%80\%99s-future-buildingresilien ce-tourism [Accessed 10 July 2019]

Fabry, N. and Zeghui, S. (2019) Resilience, tourist destinations and governance: an analytical framework. Retrieved from https://hal.archives-ouvertes.fr/hal-02070497/ document [Accessed 10 July 2019]

Filimonau, V. and De Coteau, D. (2019) Tourism resilience in the face of integrated destination and disaster management. International Journal of Tourism Research, Online, Retrieved from https://onlinelibrary.wiley.com/doi/pdf/10.1002/jtr.2329 [Accessed 3 November 2019

Government of Nepal Ministry of Culture, Tourism and Civil Aviation (2018) Promoting Private Sector Engagement in Climate Resilient Tourism. Retrieved from https:// www.climatefinance-developmenteffectiveness.org/regional-dialogue-event/img/day 2/S4.2-Prompting-Private-Sector-engagement-in-Climate-Resilient-Tourism.pdf [Accessed 22 July 2019]

Government of Jamaica Ministry of Tourism (2019) Jamaica takes the lead on Global Tourism Resilience Management. Retrieved from https://www.mot.gov.jm/news-releases/jamaic a-takes-lead-global-tourism-resilience-management [Accessed 3 November 2019]

Halliday. (2018) Destination Resilience and Sustainable Tourism Development. Tourism Review International, https://www.academia.edu/38104793/Destination_resilience_ and_sustainable_tourism_development [Accessed 9 July 2019)]

Hassler, U. and Kohler, N. (2014) Resilience in the Built Environment. Building Research and Information 42 (20: 119-129

Haver, A., Akerjordet, K. and Furunes, T. (2014), Wise emotion regulation and the power of resilience in experienced hospitality leaders. Scandinavian Journal of Hospitality and Tourism 14 (2): 152-169

Jones, P. and Comfort, D. (2018) Bouncing Back: A commentary on resilience in sustainability narratives. Journal of Public Affairs. Retrieved from https://onlineli brary.wiley.com/doi/full/10.1002/pa.1689 (Accessed 6 August 2019)

Karatepe, O.M. and Karadas, G. (2015), Do psychological capital and work engagement foster frontline employees' satisfaction? A study in the hotel industry. International Journal of Contemporary Hospitality Management 27 (6): 1254-1278 
Lambert, E., Hunter, C., Pierce, G.J. and Macleod, C.D. (2010), Sustainable whalewatching tourism and climate change; towards a framework of resilience. Journal of Sustainable Tourism 18 (3): 409-427

Lew, A.A. (2013), Scale, change and resilience in community tourism planning' Tourism Geographies 16 (1): 14-22

Luthe, T. and Wyss. R. (2014) Assessing and planning resilience in tourism. Tourism Management 44 (2014): 161-163

MacKinnon, D and Derickson, K.D. (2013) From Resilience to Resourcefulness: A critique of Resilience Policy and Activism. Progress in Human Geography 37 (2): 253-270

Martin, R. and Sunley, P. (2014) On the Notion of Regional Economic Resilience; Conceptualisation and Explanation. Economic Geography 15 (1):-1-19

Matin, N., Forrester, J. and Ensor, j. (2018) What is equitable resilience? World Development 109 (2018): 197-205

Meerow, S. and Newell, J.P. (2016) Urban resilience for who, what, when, where and why?' Urban Geography, Retrieved from http://www.tandfonline.com/doi/full/10. 1080/02723638.2016.1206395\#.V4UeoPkrKUk [Accessed 27 September 2017]

Ministry of Environment, Natural Resources Physical Planning and Fisheries (2014) Dominica National Land Use Policy Retrieved from http://www.lse.ac.uk/Grantham Institute/wp-content/uploads/laws/8494.pdf [Accessed 21 July 2019]

Orchison, C. (2013) Tourism business preparedness, resilience and disaster planning in a region of high seismic risk: the case of the Southern Alps, New Zealand. Current Issues in Tourism 16 (5): 477-494

Orchison, C. and Espiner, S. (2018) Fast and Slow resilience in the New Zealand Tourism Industry in Lew, A.A. and Cheer, J., Eds., Understanding Tourism Resilience: Adapting to Environmental Change, pp. 102-126. London: Routledge

Powell, R.B., Green, T.F., Holladay, P.J., Krafte, K.E. and Duda, M., Nguyen, M.T., Spencer, J.H. and Das. P. (2017), Examining Community Resilience to Assist in Sustainable Tourism Development Planning in Dong Van Karst Plateau Geopark. Retrieved from Vietnam https://www.tandfonline.com/doi/abs/10.1080/21568316.20 17.1338202 (Accessed 21 March 2018)

Prayag, G., Orchiston, C. and Pennington-Gray, L. (2018) Tourism Management Perspectives Special Issue: Resilience of the Tourism and Hospitality Industry. Retrieved from http://media.journals.elsevier.com/content/files/79960-20054637.pdf [Accessed 10 July 2019]

PricewaterhouseCoopers (2017a) What's the most important capability for business today? Retrieved from https://www.pwc.com/gx/en/services/advisory/consulting/ risk/resilience/publications/enterprise-resilience.html [Accessed 27 September 2017]

PricewaterhouseCoopers (2017b) Business Resilience. Retrieved from https://www.pwc. co.uk/services/audit-assurance/risk-assurance/services/business-continuity-manage ment.html [Accessed 27 September 2017]

Queensland Tourist industry Council (2018a) Building a resilient tourism industry: Queensland tourism climate change response plan. Retrieved from https://www.qld. gov.au/_data/assets/pdf_file/0036/68697/building-resilient-tourism-industry-qld-ccrplan.pdf [Accessed 18 July 2019]

Queensland Tourist industry Council (2018b) Building a resilient tourism industry plan officially launched. Retrieved from https://www.qtic.com.au/news/19f111ce-e363e811-a83e-000d3ae0a6cf/ (Accessed 18 July 2018)

Queensland Tourism Industry Council (2019a) Tourism Destructive Technologies Project. Retrieved from https://www.qtic.com.au/workforce-development/tourism-disruptivetechnologies-project/ [Accessed 20 July 2019] 
Queensland Tourism Industry Council (2019b) Digital Disruption. Retrieved from https://qticazure.blob.core.windows.net/crmblobcontainer/1809011\%20Project\%20S cope\%20-\%20Digital\%20Disruption\%20-\%20External.pdf [Accessed 20 July 2019\}

Samoan Tourism Authority (2017) Climate Early Warning System and Tourism in Samoa. Retrieved from http://www.samoatourism.org/articles/184/climate-early-warning-sy stem-and-tourism-in-samoa [Accessed 5 November 2019]

Sarda, R. and Pogutz, S (2018) Corporate Sustainability in the $21^{\text {st }}$ Century: Increasing the Resilience of Social-Ecological Systems. London: Routledge

Schipper, E. L. F. and Langston, L. (2015) A Comparative Overview of Resilient Measurement Frameworks: Analysing Indicators and Approaches. Retrieved from https://www.odi.org/sites/odi.org.uk/files/odi-assets/publications-opinion-files/9754. pdf [Accessed 1 October 2017]

Scott, D., Hall, C. M. and Gossling, S. (2016) A review of the IPCC Fifth Assessment and implications for tourism sector climate resilience and decarbonization. Journal of Sustainable Management, Online, Retrieved from https://www.tandfonline.com/doi/ abs/10.1080/09669582.2015.1062021 [Accessed 6 November 2019]

Sharifi, A. and Yamagata, Y. (2014) A conceptual framework for assessment of urban energy resilience. Retrieved from https://ac.els-cdn.com/S1876610215013545/1s2.0-S1876610215013545-main.pdf?_tid=e294fa1a-ad91-11e7-9e9d00000aab0f27\&acd nat=1507622954_14c75dc4e7de0b430742e991f1fd3fff [Accessed 27 September 2017]

Sydnor-Bousso, S., Stafford, K., Tews, M. and Adler, H. (2011), Towards a Resilience Model for the Hospitality and Tourism Industry. Journal of Human Resources in Hospitality and Tourism 10 (2): 195-217

Tibay, V., Miller, J., Chang-Richards, A., Egbelakin, T., Seville, E. and Wilkinson, S. (2018), Business resilience: A study of Auckland hospitality sector. Procedia Engineering 212: 1217-1224

Thomas Cook Group (2018) Making a Difference with Every Holiday: Sustainability Report 2017. Retrieved from https://www.thomascookgroup.com/wp-content/uplo ads/2018/03/ThomasCook_SR2017_Final.pdf [Accessed 10 July 2019]

The World Bank (2017) Tanzania: Resilient Natural Resource Management Plan for Tourism and Growth. http://projects.worldbank.org/P150523?lang=en (Accessed 21 July 2019)

Twinning-Ward, L., Perrottet, J. and Niang, C. (2017) Resilience, Sustainability and Inclusive Growth for Tourism in the Caribbean. Retrieved from https://blogs.world bank.org/psd/resilience-sustainability-and-inclusive-growth-tourism-caribbean [Accessed 10 July 2019]

Vale, L.J. (2013) The politics of resilient cities: whose resilience and whose city? Building Research and Information 42 (2): 191-2011

Zellmer, S. and Gunderson, L. (2008) Why Resilience May Not Always Be a Good Thing: Lessons from Ecosystem Restoration in Glen Canyon and the Everglades. Nebraska Law Review 87 (4): 894-945 



\title{
When Marginalising the Role of Local Participation in Heritage Conservation Policies: Evidence from Erbil Citadel
}

\author{
By Mohammed Awadh Jasim* , Laura Hanks ${ }^{ \pm}$\& Katharina Borsi*
}

This paper reviews the top-down vision of Erbil Citadel's local community role in two conservation processes conducted upon its built heritage, but with further concentration upon its current revitalisation process, since it is still taking place on the ground. It aims at demonstrating the problematic nature in valorising the presence and thus, the participation of the locals in the current revitalisation process, linking its latent reasons to the loose mechanism employed to attain its goals. It is concluded that the lack of experience of site authorities regarding how to link the touristic goals of the policy to the sociocultural potentials of the site has led to overlooking the role of the locals regarding the revelation of these potentials, and consequently to their marginalisation in the revitalisation process. The paper also draws initial findings about the potential causes that often drive local conservation processes to ignore local participation, recommending further investigation in this regard.

Keywords: Local participation, Heritage conservation, Marginalisation, Doha ICOMOS (International Council on Monuments and Sites), Erbil Citadel.

\section{Introduction}

Local participation of the inhabitants is often regarded as a vital pillar for setting genuine policies of heritage conservation owing to the diverse cultural potential that their knowledge may contribute to these policies (Jasim et al. 2017, ICOMOS 2013a, 2013b). True deciphering of the site's histo-cultural story, as an interlocking conglomeration of specific sociocultural values, vernacular traditions and bygone events, and thus their realistic employment within the conservation policy, might therefore be far-fetched without the concrete engagement of the inhabitants (Salazar 2010, Park 2014). The latter's contributions emerge from the site's multi-layered cultural reality, which demonstrate built heritage as multifaceted living assets rather than physical residues from the past to be visited. As such, factual engagement of the locals can truthfully boost the site's futuristic policies including those cultural heritage-based touristic ones (Naef and Ploner 2016). More importantly, it can protect the site from some

\footnotetext{
*Architecture Department Faculty Member, Koya University and Tishk International University, Kurdistan.

${ }^{ \pm}$Associate Professor, Department of Architecture and Built Environment, University of Nottingham, UK.

*Assistant Professor, Department of Architecture and Built Environment, University of Nottingham, UK.
} 
loose strategies of the site's authorities that usually present 'heritage as... conflicting uses and purposes' in the way its cultural potential is 'marketed...in tourism contexts', which leaves heritage 'largely unrecognised or underrepresented' (Park 2014: 3). Despite this having led to a globalisation of the legitimacy of local participation in formulating heritage conservation policies, more than one conservation process conducted upon Erbil Citadel has shown what contradicts this discourse (Jasim et al. 2018). This, in turn, calls for an investigation into the reasons behind this contradiction, which is what the study aims to cover here. In fact, the unique residential features of the settlement haves robustly contributed to rooting the nature of Erbil's cultural potential, which supposedly should make the inhabitants' contributions important for revealing the potential within the new tourist shift of the site. Excluding them from participating in formulating the revitalisation policies of the site is therefore controversial indeed.

Hence, the paper aims to demonstrate the preliminary consequences of excluding local participation in Erbil Citadel's current revitalisation process, and instead seek any local views that may support the touristic aim envisaged for the revitalisation policy. This perhaps reveals the extent to which local participation can serve this aim, and thus to what extent it is taken into consideration by the site authorities. As a methodology, the study adopts a qualitative approach whereby it can concisely make the link between the heritage's cultural potential and the role of the locals' contributions in revealing and employing them within the tourism market. To achieve this, a synthesis of tools is utilised here. Firstly, the paper reviews some key literature that demonstrates the correlative relationship between the site and its inhabitants throughout history, enabling a precise positioning of their role as a vital tool to this end. Specific studies are debated here that firstly settle the affirmative aspects of this relationship in addition to revealing the potential that can be provided by the locals to the current policy of Erbil revitalisation, particularly the revelation of the key issues that its touristic shift involves.

To enable a critical investigation of these issues, firstly the study debates the contributions made by two conservation processes upon Erbil's built heritage and the role entrusted to its local community in this regard. In particular, the paper reviews what ICOMOS reports about the contradiction between what the site's authorities emphasise regarding the significant residential-cultural value of the site, and the fact that it lacks a genuine reference to the role of its local community within the current revitalisation process regarding both detection of its cultural attractions and thus achievement of its touristic shift. Secondly, it conducts some specific interviews with some key figures amongst the site inhabitants, the local authorities and the global experts of the revitalisation regarding repercussions of these issues upon the overall cultural value of the Citadel's built context. This, ultimately, enables a critical discussion, and thus a viable conclusion concerning the achievement of the site's touristic aim through the role of local participation. As part of the findings, the potential reasons behind the marginalisation of the local views might be attributed to the 
Iraqi local rules of heritage conservation, so further studies are recommended in this respect.

\section{A Contradictory Vision of the Locals' Role in Conservation Processes: A Concise Review of the Literature}

Despite its importance, the role of local participation may represent a challenge for conservation processes of some built heritage sites, especially for some authorities that do not celebrate rich experiences in this regard. This, in fact, is due to an ill-conceived vision that can draw upon the purposeful potential of this role, which, because it may lack a professional narrative style, is often understood as crude contributions that seem superficial or impractical. Otherwise, examples of the feasibility of this role are numerous, for instance, the ICOMOS Charters of 1999, $2002 \& 2004$ consider the inhabitants have the capacity to comprehend the cultural spirit and biography of the built context of the site, and thus necessitate their contributions in revealing heritage histo-cultural values and events. Huang (2006) observes the deep-rooted correlation between the site and its inhabitants as a unique characteristic, which grants them the ability to deepen some cultural dimensions of the context. This consequently can assist in resuscitating a broader image of the requirements that the site's development entails, and thus explore new guides that maintain the validity of the conservation policies to be more responsive to any future changes. Based on their continuous coexistence with the site, Huang et al. (2012) and Yang et al. (2010) state that their views may demonstrate valid solutions to protect against any physical deterioration of the site. In the field of heritage's 'marketdriven tourism', Johnston (2003) and Staiff et al. (2013) affirm that engagement of the aboriginal inhabitants facilitates setting a good management plan of heritage conservation, since it is conditional on the extent of a proper revelation of its cultural assets, which is a task that often dictates the factual participation of the inhabitants.

All of this should depict conservation policies as 'community-based partnerships', which entail giving a more 'effective' role for the views at the grassroots level of the site (MacDonald and Jolliffe 2003: 307), making ultimately the goals of these policies more attainable. As part of this, Thapa (2007) and Wager (1995) note that achievement of long-term heritage policies that are able to perpetuate heritage's tangible and intangible assets must include local participation, which entails a 'decentralised strategy...based on co-decision methodology between the site's authority and inhabitants' to formulate its conservation policies (Jasim et al. 2017: 296). This enables the involvement of multiple perspectives and a broad range of knowledge, and thus the 'dynamic participation of purposeful concepts [consequently] a more comprehensive process of decision-making' (Jasim et al. 2017: 296-297). However, according to Avrami et al. (2000), the extreme reliance on the general rules of the articles stipulated by some global charters by site authorities when drawing up heritage 
conservation policy often hinders the genuine activation of such roles that local participation may play.

However, the locals' excessive interpretation of heritage is sometimes seen by authorities as holding back some innovative global techniques of heritage conservation, creating a state of vagueness regarding the exact role that can be entrusted to them. Furthermore, their involvement can create a state of intricacy concerning coordinating the responsibilities and priorities among the site's authorities and inhabitants, which, in the long-run, also weakens this role. Aas et al. (2005), and Su and Li (2012) attribute this to a kind of inconsistency among them, which often results from incompatibility regarding planning for the site's economic and touristic potential. For instance, the inhabitants' subjective narratives regarding the site's cultural values might drive to undervaluing the cultural significance of the site globally. Consequently, instead of streamlining the steps of formulating its conservation policies, their narratives may lead to complicating the overall management plan of conservation (Dicks 2000, UNESCO 2005, Poria and Biran 2006, Thapa 2007). More importantly, the authorities usually seek to globalise the site to enable heritage to become more open-ended to accommodate tourists' tales and visitors' interpretations in order to increase the cultural merits and economic impacts that can be brought to the entire place (Chhabra et al. 2003, Park 2014). Yet, this can sometimes challenge some local visions that often see heritage as a fixed and unchanging entity.

Within this discourse, the role of local communities of some Asian Islamic heritage sites has been overlooked and replaced with what heritage specialists narrate concerning strategies of their conservation. In fact, the task of conservation of Iraqi built heritage, which Erbil Citadel is part of, has demonstrated the worst-case scenario when the task of its conservation has been entirely assigned to some local decision-makers. Some local experiences have proven that those decision-makers have set conservation policies of some local sites depending on their personal experience. In contrast, on some other sites, an opportunity for involvement has only been given to some global heritage experts, whilst the role of their inhabitants has been entirely disregarded. Indeed, both of these approaches have resulted in some frustrating outcomes upon these sites. An example of this comes from Babylon heritage site, which has been temporarily removed from the WHL (World Heritage List) immediately after such policies. It has become well-known that the contributions of the local professionals were left aside within that process, which if they had participated, might have brought about a significant change (Jasim et al. 2018). In fact, some other local sites, where conservation processes are still ongoing, portend to similar outcomes, particularly stating that their future aims require efficient contributions of their local communities, whereas initial results of their policies indicate the opposite.

\section{Positioning Erbil Citadel within this Context}

Erbil Citadel is a fortress of deep-history, tailored from diverse cultural values and historical events (MacGinnis 2014), and resulting from a 'successive 
rebuilding... over thousands of years' (Brammah 2009a: 67). It rests on the top of a mound-slope at the centre of Erbil, the Capital of Iraqi Kurdistan. From a historical-urban perspective, the Citadel's oval form has contributed to shaping the urban form of Erbil city, as there have been successive circular urban rings surrounding the Citadel including its axial routes that stem from the mound towards the outside of the city (see Figure 1). Its unique trait of being continuously inhabited for more than 6000 years, (since the Neolithic age) (Novacek et al. 2008, HCECR 2008, Brammah 2009a, MacGinnis 2014) should be regarded as a surplus value for its inhabitants, which sanctions their participation in drawing up the site's future policies. This may enable a more transparent transmission of its diverse cultural values of construction on the site.

In particular, the current traditional urban fabric of the site, which is assigned to the Ottoman period (UNESCO 2015), puts its locals in the foreground for partaking in any process of conservation as being the true knowledge-holders of this period. The built context of this period mirrors a strong cohesion and coherence of social structure and thus urban structure that was considered to be a consequence of the conformist social relationships, and through the Islamic canon, which celebrates the concept of social neighbourhood.

Hence, the general social values and traditions among the locals have added a sense of congruence and social harmony consolidating the social networks, and thus the social criteria of the site. This in fact also grants the inhabitants primacy in knowing the site very well, making them familiar with its diverse historical events and sociocultural values (Southgate 1840, Bornberg et al. 2006, HCECR 2008, SOITM 2013). From a tourist perspective, despite the unstable political circumstances, the GBTKRG (2019) reports show that local tourism has increased dramatically in Kurdistan aiming to reach 3.5 million visitors by the end of 2019. This has led to further consideration of how to promote cultural heritage tourism locally, while the role of local communities still requires real meditation particularly in terms of highlighting the potential of built heritage sites. Erbil Citadel, in particular, has witnessed an increasing number of visits, especially in recent years. According to the Head of the High Commission for Erbil Citadel Revitalisation 'HCECR', than 53,000 visitors in 2016 (Ekurd 2017). Mostly, visitors celebrate the site's urban heritage including some local folklore and social norms that have materially contributed to its emergence, which is often referred to as a value attributed to its residents (MacGinnis 2014, Brammah 2009a). All of this should ultimately give their participation priority in formulating the site's future plans within any process of conservation.

\footnotetext{
${ }^{3}$ One of the authors was part of the HCECR in $2007 / 8$ as a Senior Architect.
} 
Figure 1. A: Erbil Citadel as a Cultural Built Heritage, an Aerial Image for the Site in 1951; B: Erbil City, which shows Erbil Citadel at its Centre, which has contributed to the Current Layout of its Circular Urban Form; C: Map of Iraq showing Erbil City

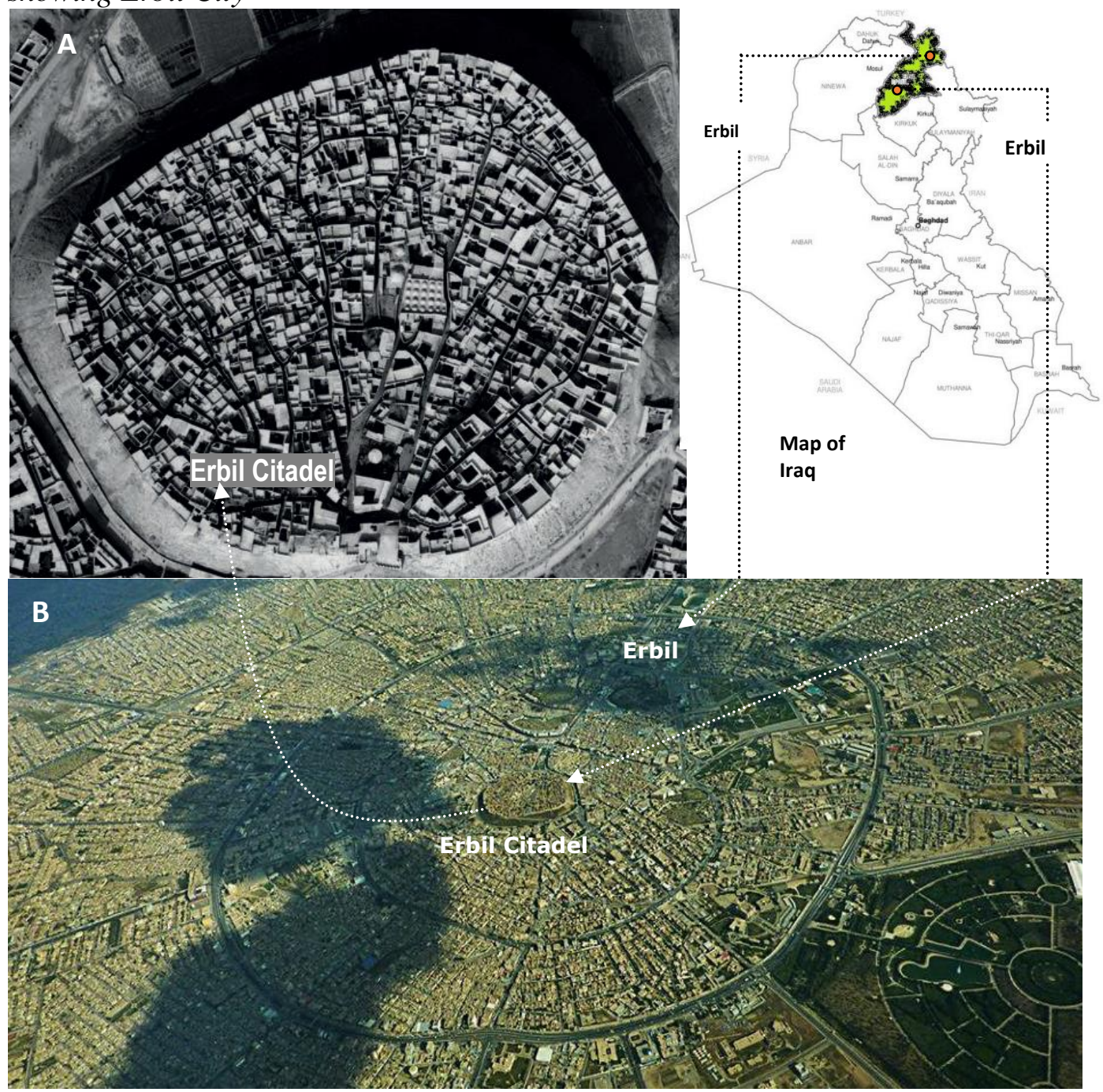

Source: A: Pitt-Rivers Museum, Bradford Collection, 1998.296; B: Erbil Citadel private library; C: modified from Erbil Governorate private library.

\section{Site-based Indications Debilitate Local Participation}

\section{First: Within Erbil Citadel Renovation Process}

In 1979, however, the renovation process carried out on the site was completed according to an explicit model of top-down decision-making, resulting in a negative correlation with the site's cultural ethos and the extent to which it corresponds with its local privacy. Based on a study by Brammah Huszar and Associates on the site (2009), the renovation made a series of urban and architectural changes, such as 'the demolition of the historical south gate' 
including the site's central area, which left real repercussions on the built context, as if they were 'deliberate demolitions' of the site (Huszar and Associates on the site (2009: 68) (see Figure 2). Both the gate and the central area have been repeatedly emphasised as substantial parts of the context for their deep-antiquity and thus their symbolic values. Their demolition, therefore, has jeopardised the site's deep residential-cultural values, reflecting an 'overwhelming feeling' about authenticity of the Citadel's built heritage as a historical symbol of the place (HCECR 2012a: 1).

In fact, the key purpose behind the renovation is to improve accessibility and flow of traffic, from and to the site for the locals in line with the contemporary life of Erbil. This, for authorities, can prevent the departure of the inhabitants, and thus prevent the repercussions that may strike the site culturally, as it creates a gap between the site's sociocultural values and their origins rooted in its residential context. Whereas this aim is apparently valid, still the tools for its achievement are perhaps worthless. If the site authorities represent one of the main two powers that should make decisions for the renovation, its local community is regarded the second power who can give valid solutions in this regard based on their uninterrupted deep correlation with the site (Jasim et al. 2017). Therefore, if the demolitions perhaps indicate a clear lack of knowledge that the renovation team possessed about the site, this supposedly should redirect the process towards the engagement of the inhabitants. Their contributions should have been seen as a base, or more precisely a 'stable network [of] effective shared views' towards more realistic development of Erbil's urban and architectural assets (Jordan 1990: 327). A development that can carefully respond to the contemporary life, but meanwhile maintain the traditional identity of the context, as the inhabitants are more familiar with the issues and potentials of its residential-urban fabric. Along with the desired contemporaneity, their vibrant input, therefore, can tailor the renovation policy more with this fabric to be more attached to its tangible and intangible tenors.

Yet, the HCECR (2012b \& 2012c) affirm that the renovation has shown the complete exclusion of any local contributions, even those of stakeholders and professionals. The renovation policy attributes this to the non-stop departure of those professionals and stakeholders, resulting from the continuous physical 'damage[s]' that the built context has witnessed at that time (Brammah 2009a: 68). Accordingly, the local authorities decided to reinstate the site to its original assets before the renovation, whereas the HCECR (2012c) points out that the locals' contributions should be well-thought-out to be efficiently included this time. This, consequently, has urged UNESCO's Guidelines (2014) to consider the inhabitants' contributions as an imperative for the "assessment" of any new plan to revitalise the site, including its "future aim". After 2007, therefore, a thorough revitalisation process was initiated to restore the site's genuine urban image. 
Figure 2. "Left": The Citadel in 1951, before the Renovation; "Right": The Citadel after 1979, after Renovation

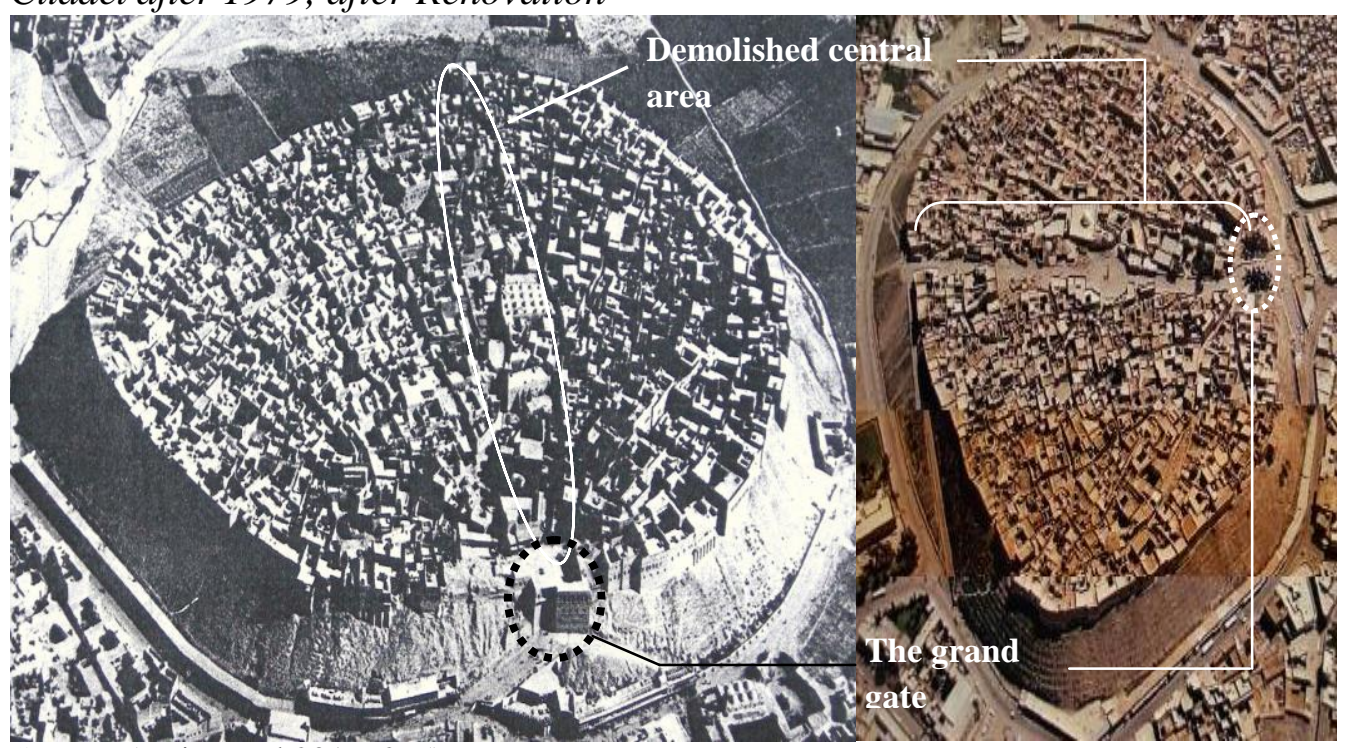

Source: (Jasim et al 2017: 295).

\section{Second: Within Erbil Citadel Revitalisation Process}

Based on Brammah (2009a, 2009b), HCECR (2012c), and UNESCO (2013 $\& 2014$ ), the revitalisation process should be driven by the general frame of the broad topological and cultural-traditional features of the site. To achieve this, the role entrusted to the decentralised power strategy between the site's authorities and inhabitants should be truly activated, which empowers the latter to be engaged in efficient negotiations towards a complete revelation of the sociocultural values and events, or any other ruinous features of the Fortress. Whilst the context is carefully being traced to be well-reinstated to its authentic settings, it is being mapped out to serve global heritage tourism, as a substantial goal envisaged for the site, based on its rich cultural potential, which stretches back thousands of years (MacGinnis 2014). In fact, its unique feature of being continuously inhabited for six thousand years, on the one hand, enriches the site's current diverse values, meanings and assets, and thus its touristic shift. On the other hand, it presupposes the locals' role in formulating its revitalisation policies (HCECR 2012c, SOITM 2013). In particular, the Citadel's built context is an explicit representation of its cultural context, where the latter is an integral part of its social context formed by its inhabitants over its deep history, making these three contexts overlapping and inseparable from one another. Accordingly, any attempt to invest and utilise its historical-cultural context within heritage tourism may require the genuine contribution of its locals, particularly after the site's Ottoman period.

During those periods and afterwards, Islamic norms left tangible impacts upon the formulation of the site's urban and architectural character as an explicit response to its social-cultural context (HCECR 2008, SOITM 2013), making a valid reading of these contexts substantially contingent upon the tangible participation of some site-based contributions. The World Heritage Committee, 
therefore, recommends that 'links and sense of belonging of the ... inhabitants [should] represent important aspects for a long-term revitalisation of Erbil Citadel', which may robustly contribute to its touristic goal (2014: 16). For the Committee, the Citadel is a popular venue that socially and culturally gathers the inhabitants, particularly through some cultural-religious activities in the central public zone. Consequently, any efforts to revitalise the site, including planning for its touristic potential, should consider this aspect as a determining factor in restoring the built context to its authentic setting before the renovation.

Brammah (2009b), who worked on the preparation of the revitalisation Master Plan, also believe that local engagement would boost local-based support for the site's future decisions. Accordingly, they recommend enacting new bylaws and regulations for this purpose that serve 'the creation of a culture of care for the Citadel and its built heritage', where the locals will act as a cornerstone to fulfil this (Brammah 2009b: 92). Perhaps, the importance of this comes from what the Implementation Action Plan (2009) of the revitalisation entails, which states that the first threshold in the revitalisation process should focus on how to establish a broad database of historical and cultural knowledge that facilitates the objective construction of the site policies. To meet this, the inhabitants should be seen as a living informative base of data 'to deliver the vision of the revitalisation', and thus building 'strong partnerships' with them is essential (Brammah 2009b: 22). More importantly, 'engag[ing] the residents' would sustain 'significance' of the site as a residential settlement, which boosts 'the revival of its identity', and thus its touristic goals (Brammah 2009b: 26). In fact, the UNESCO Guidelines on the Citadel Conservation (2014) consider the locals' role as a 'key principle' in gathering 'oral and physical documentation' about the histo-cultural biography of the site that can feed the 'input' and 'assessment' of the revitalisation (UNESCO 2014: 17-18). The Guidelines therefore quote on page 12 of the Burra Charter plan that the locals should be involved within the whole process of revitalisation.

However, the current progress of the project contradicts this, and foreshadows some contentious outcomes, especially with regard to meeting its touristic aims (ICOMOS, 2014). Whereas the revitalisation's initial steps indicate the real absence of local participation, it is expected that the site may face a similar fate of Babylon to be 'removed from UNESCO WHL' if the revitalisation continues without change to its current policies (Ekurd 2017). Part of this change may come from realistic contributions stemming from the reality of the site itself rather than what experts' contributions dictate.

\section{A Non-integral Vision towards the Role of Local Participation}

Despite the potential need for some site-based workable views, more than one study showed that this issue did not receive real consideration by site authorities. For instance, a study on "Repercussions of Singularity of Authorities" in making conservation decisions states that planning for 'the future aspirations of the revitalisation policy rests with the [authorities] more than the site inhabitants' (Jasim et al. 2018: 82), which portends to fewer encouraging results about the 
expected role of the latter. In fact, the top-down plan for the future of the site after its revitalisation is perhaps the main reason for this, since the value of the locals in sustaining its tourism prospects does not seem to be included here, making their raw views on the progress of the revitalisation policy unnecessary. For the authorities, continuity of the unique residential feature of the site as being continuously inhabited for millennia will not be a key aim for the site after its revitalisation. This feature will be used as a complementary tool that supports the new touristic aim of the site, and thus 'will be re-employed just to boost' the Citadel's built heritage within 'global tourism [as] a brand for Kurdistan' (Jasim et al. 2018: 82). The need is for a profession-based vision that can make change, which adopts expert views more than being a local-based vision resting on the "raw views" of the inhabitants.

The Ministry of Culture and the General Tourism Commission in Erbil (which are strongly connected to the revitalisation policy) affirmed, in direct interviews conducted in 2016, that the touristic shift of the Citadel demands some innovative views of global experts. Their rich experiences of heritage conservation can nourish the revitalisation with some novel "plans", "proposals" and "recommendations" that would have a palpable effect on the fulfilment of the touristic shift. Operating the cultural potentials of the site may require reemploying them as part of an interconnected loop integrated into new complementary activities based on its urban and architectural potential, and this largely entails some expert contributions. This, in turn, may create change, opening the site towards some global investment bringing finance to the revitalisation process whereby its policy can continue, and this, indeed, is what UNESCO/Iraq Office suggested in 2016. Yet, regardless of the controversial vision of the continuity of the historical-residential trait as a predominant value of the site, revival of the obsolescence of different sociocultural potentials should act as part of the change, thus an efficient complementary tool that supports the touristic aim (HCECR 2012c, Brammah 2009a). Their diverse values should thereby be allowed to grow, increasing the accumulation of their positive impacts, thus maintaining a progressive nature for the touristic potential of the built context (Mitchell 2008). Considering that these values are produced as part of the 'social practice' of the inhabitants (Smith, 2012), the local-based contributions are basically the most appropriate tool that can engage with them according to what may facilitate understanding the influence of the local culture on their emergence (MacGinnis 2009). When people have 'culture...norms...memories...ideas... feelings... meanings... conceptions' shared with the site, this makes an interpretation of such an influence possible for them (Mahmud 2007: 40). Consequently, it enables an intact reading of the overlapped relationship between the cultural and the urban context of the site, since the cultural context of Islamic built heritage is a verbatim interpretation of its sociocultural impacts (Abu-Lughod 1987, Rico 2017). Jasim et al. (2018) may provide site-based evidence of this, stating that: 
The locals are able to 'reveal some social norms inherent in the Citadel; detecting many of its obsolete architectural details; picturing some key historical stories submerged in the site's cultural layers; and thus, their performance as a "storytelling" for the recreational journey of this built heritage' (Jasim et al. 2018: 82-83).

Accordingly, precise analysis of 'in-depth' views of its aboriginals allows for a realistic understanding of how these impacts have contributed in constructing the urban and architectural context of this built heritage, and thus their required reemployment within its touristic shift (Mahmud and Al-naim 2006, Assari et al. 2012). As an Ottoman style, for instance, the architectural and urban context of the site has suffered different destructions over the last two centuries and are now mostly in ruins (HCECR 2012c), which makes reinstating the context to its original Ottoman setting challenging, since it substantially requires understanding the genuine assets of its sociocultural potential. Conservation experts are therefore difficult to be considered here as an elite who knows everything about this built heritage. Consequently, their contributions are perhaps unable to make the restoration of any ruined part of its non-physical entity possible, and so this task should not be completely entrusted to them. The site-based contributions instead are often seen as "the foundation" upon which tasks should begin. Nevertheless, the first decision that was made for the site revitalisation was the evacuation decision that aimed to clear the site of its inhabitants, and all of the revitalisation's other major decisions were made afterwards (ICOMOS 2014). This, in fact, suggests that the site's local authorities' vision of the revitalisation as an integral and overlaid policy is incomplete and lacks rationale, and is perhaps mostly held in subjective considerations. This is what one of the key global experts of the revitalisation confirmed in the study in 2016. The residents were displaced early off-site and before any consultations with the experts whose experience may demand some site-based local views in order to clearly understand some very local assets, especially those that have taken root in the daily life of the local community. The inhabitants, on the other hand, also embraced this expert viewpoint, confirming to the researcher that the evacuation made them unable to participate due to their early departure from the site in exchange for some compensation. For them, confining the setup of the revitalisation policy to mutual efforts shared between some global and local specialists seems to have been predetermined earlier even before the revitalisation process began.

Hence, if we appreciate the decision to make the site globally recognised, still the step to clear the Citadel of its inhabitants was premature since it contradicts and even debilitates the tourist aim of the site when confining the plan to the total domination of views of specialists. In fact, the loose approach behind this step, and thus the disinterest of local participation, can be attributed to the site authoritiesbased initial procedures that preceded the revitalisation policy. The procedures determined the global experts as the elite who, indisputably, 'know what is good' for the site, which, in return, considered consult[ation] with local people' as something trivial (Din 1993: 329). Whereas the pertinent correlation between the social and urban contexts of the Citadel may refute this vision, the evacuation rescinds the unique feature (the continuous habitation of the site), which is 
considered by the revitalisation policy as a keystone for the touristic aim (HCECR 2012c). According to Park (2014), besides keeping the site vibrant for the visitors (proving its historical fact as a long-standing residential settlement), the existence of the inhabitants enables a qualitative understanding of the site's cultural assets based on their lived interpretations of these assets that allow open discussion with the visitor. What makes the top-down vision of the revitalisation nonrepresentational for such goals then is the ill-suited introspection of the value that this feature may bestow upon the built context (Timothy 1999).

For example, the promising change for the current policy underlies an architecturally-oriented restoration that is confined to rehabilitating the site's physical potentials, which deems the authentic retrieval of its physical structures sufficient for creating excitement, and thus attracting visitors. In fact, the policy explicitly declares that revitalising the site's physical structures 'will be enhanced by means of ... tourism and leisure activities that are compatible with...its aspirations to become a World Heritage Site' supporting Erbil touristically (HCECR 2012c: 125) (see Figure 3). Whereas the policy condones the fact that the site will be presented as a deserted context, some visitors may enjoy seeing the site celebrating its people, or their questions may demand the presence of the inhabitants. Confining its touristic shift to a purely material reading focused on rehabilitating its physical structures only means the current policy drives the site to misuse the value of its traditional-residential character.

The ill-thought-out planning for preparing the huge budget that the revitalisation requires, on the other hand, has also contributed to the decision of evacuation, including the marginalisation of local participation albeit indirectly (Brammah, 2009a, 2009b, HCECR 2012a). For the authorities, achieving this budget necessitates globalising the site touristically, for which the revitalisation policy considers the evacuation step as expediting the process. It allows for intensifying the expert contributions in how to bring global investors who may benefit from the spaces of the physical structures of the context after being revitalised to operate their own cultural, managerial and economic interests. Consequently, it facilitates making the revitalisation a self-funded process in addition to its multiple economic returns on the whole place. In this regard, Paris ICOMOS (2011) considers built heritage as an increasingly important constituent within the industry of global tourism, thus as an essential driver of urban development of the place. It can play a fundamental role in boosting heritagebased tourism culturally, but this also entails a precise vision that invests in its realistic potential, which considers the inhabitants as a vital part of fulfilling this. The entire displacement of the residents presents instead tangible evidence of the superficial planning of the revitalisation policy towards the achievement of this aim, as the existence of the inhabitants is actually a value for the site which could largely be supportive for its touristic shift.

Through the admittance of the site to the World Heritage List, the ICOMOS Report (2014) also refers to this issue when repeatedly asserting the significance of the site having been inhabited for millennia, and then suddenly being socially deserted. For instance: 'Erbil Citadel stands alone for its continuity of settlement...; the millennial continuity of occupation of the Erbil site is also attested to be the 
remarkable permanence of its name...,' (ICOMOS Report 2014: 80-81). However, 'the fact that Erbil Citadel is currently uninhabited detracts from its sense of place as a town....and in this regard the...revitalisation formulas appear excessively [to] not pay attention to the regeneration of the social fabric' within the Citadel (ICOMOS Report 2014: 80-86).

Therefore, ICOMOS considers the existence of the inhabitants as a substantial factor towards the achievement of its futuristic aims, affirming that:

It is strongly needed...as of utmost importance for the future and long-term conservation of Erbil Citadel's significance. ICOMOS recommends that the HCECR takes into account the role that the previous residents may play in the revitalisation process... and foresees the return of former inhabitants' (ICOMOS 2014: 87).

Doha ICOMOS (2014), therefore, asserts the importance of the role of the social constituents of the Citadel to attain its touristic shift, where the site should be recognised as an interrelated and overlapped structure of urban and architectural growth, of parts rooted in a "one-whole". As such, the revitalisation should be completely integrated into local contributions and backed up by a continuing planning process, while the final success of its policies is ultimately conditional upon a local feasible follow-up and the residents' role should be an essential part of it. Their role can assist in formulating the diverse criteria of the site's sociocultural values that contributed to the configuration of 'the traditional character' of some of its deteriorated physical structures. This, in turn, facilitates identifying the chronological order of some alterations that affected the built context, and thus the retrieval of 'the sense of the place' (ICOMOS 2014: 84). Thus, for ICOMOS, the inhabitants' uninterrupted habitation of the site makes them aware of any modifications that these structures have undergone since the Ottoman early-period. Consequently, their concrete engagement assists in the precise tracing of diverse urban and architectural assets of these structures. Perhaps what authenticates the ICOMOS treatises is the robust unity of lineage that the settlement possesses that ties the ancestors to the descendants, which is one of the substantial factors that have sustained permanent habitation of the site (SOITM 2013, HCECR 2008). 
Figure 3. The Final Proposed Functions and Urban Land Use in the "Overall Master Plan", which Shows the High Priority for Tourism and its Recreational Complementary Functions that Dominate the Residential Use of the Proposal
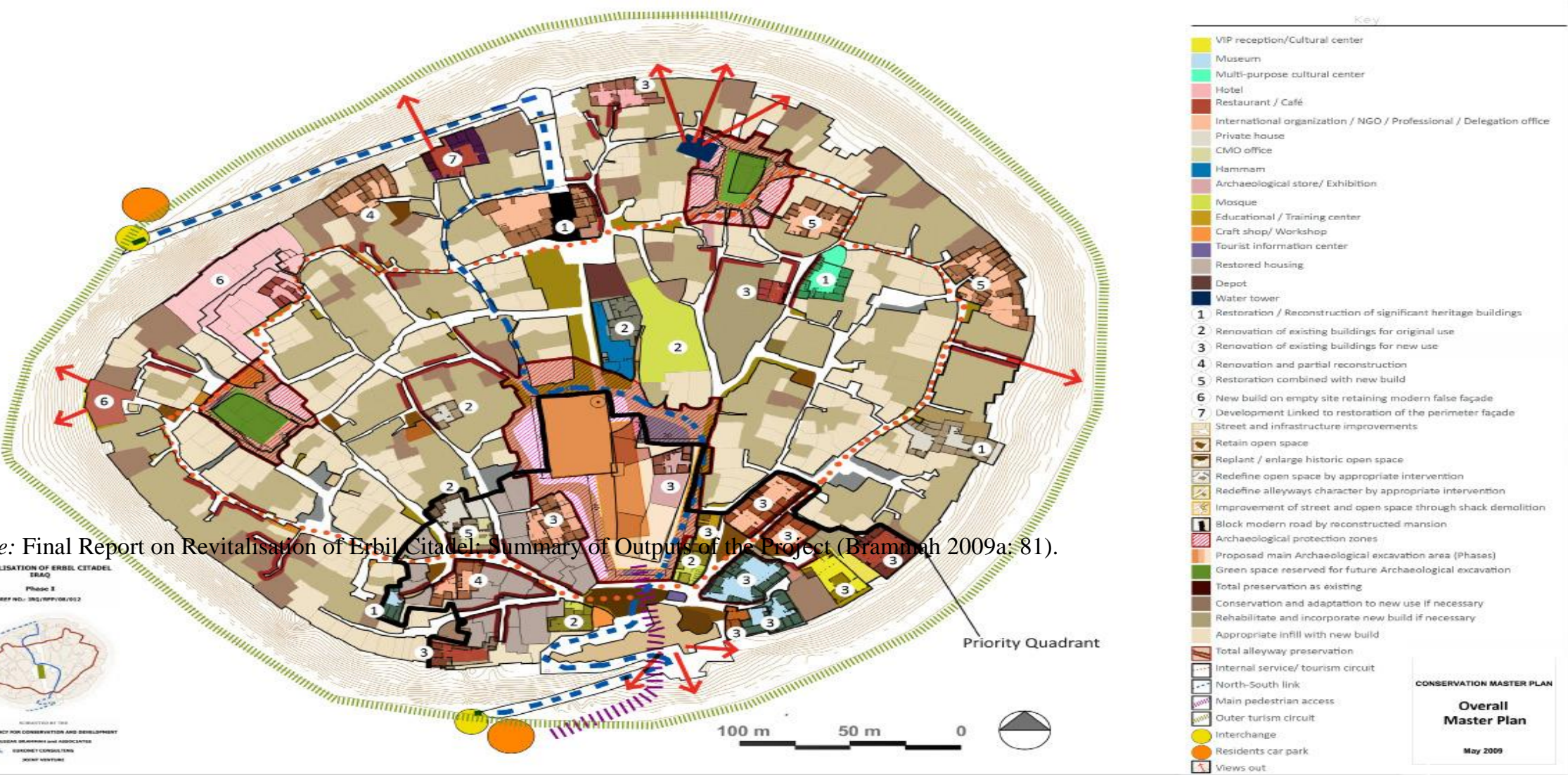
This, of course, makes the residents aware of these modifications, which in turn legitimises their participation here. The built context of the site, on urban and architectural levels represents a direct response to some essential sociocultural norms of the local community of the site and this may make local participation imperative here for the revelation of the origins of these structures. This indeed is integral because the Islamic principles of the Ottoman period have substantially contributed to shaping the current manifestation of the urban and architectural elements of the built context (Abu-Lughod 1987, Kazimee 2010). This perhaps facilitates the embedding of the site's tourist shift within the roots of the revitalisation policy, since UNESCO (2014) affirms that some site-based qualified contributions of the Citadel can help through using its 'culture and cultural heritage....as vectors for development', while perpetuating 'its transmission to the future generations' (UNESCO (2014: 5). Following such a track, the revitalisation policy also commits to what has been endorsed earlier that part of its plan is to work "on retrieving the Citadel's spirit", which is residential. Otherwise, the new tourist shift might be unable to maintain the site's traditional identity as it seems far from being governed by its unique residential character.

\section{Discussion}

Perhaps one of the key issues that should be debated firstly here is why marginalisation of the role of local participation seems deep-rooted in both the renovation and the revitalisation processes conducted on Erbil Citadel. While the renovation ignores them, the revitalisation simply does the same. The renovation had ignored the existence of the inhabitants to participate in drawing up its policies, and the revitalisation has exceeded this by knowingly displacing them from their "home", without any consideration for not just for their role but also the repercussions of such a step. In fact, the roots of this issue lie firstly in the regional criteria that many Asian heritage sites are subject to (where the Citadel lies), since they do not emphasise the importance of keeping these sites celebrating the permanent presence of their communities. Inferred from Uriely et al. (2003), Huang (2006), and $\mathrm{Su}$ and $\mathrm{Li}$ (2012) the criteria lacks a clear reference to the significance of the cultural awareness of these sites' authorities regarding deeming the locals as real representatives of their heritage and whose views often receive slight consideration in this regard. A study conducted on Nazareth Heritage in (2003), for example, shows that the residents' presence, and thus their visions, in conservation policies is 'an issue that received little attention' (Nazareth Heritage 2003: 69). Whilst this may interpret the weak application of the decentralising power strategy (between the site's authorities and inhabitants) within these criteria, according to Wilson (2003), it may prove that these criteria do not prioritise the fact that inhabitants and culture of the site are fundamentally interlinked, which therefore should carefully be addressed within any future policy related to its conservation.

On a local level, in fact, some studies concluded that the local conservation laws of Iraqi heritage sites lack a genuine action plan that consider the inhabitants 
as real representatives of the site. Bortolotto et al. (2013) mention that these laws lack 'an action plan targeting [local] communities...through meetings and workshops' (Bortolotto et al. 2013: 101), which would appropriately tailor their views with the policy setup of the site conservation. This has resulted in some specific drawbacks shared among these sites, which entail their reinvestigation within these laws, such as (Bortolotto et al. 2013: 100-101):

$>$ Little awareness about the role and benefits from decision makers to grassroots levels;

$>$ Local community-based organisations lack the official recognition and the capacity to participate in the actual development [in] community-based [cultural] resource management;

$>$ Inadequate human, technical...capacity of cultural staff at local levels to address the complex management issues and to secure effective implementation of conservation actions;

$>$ Lack of integration between institutions and local development strategies.

In fact, this series of weaknesses makes the locals' views a vassal category subordinated to the site decision-makers, which often leads to weakening their appreciation of the conservation plan, or even perceiving it 'as a restriction' that limits their contributions (Bortolotto et al. 2013: 101). Obviously, repercussions of this top-down vision have combined to make the mechanism to implement the Citadel's revitalisation policy contradictory to its aim, as evidenced by the evacuation. The latter unwillingly drags the Citadel's tourist purpose behind a mechanism that may permanently confiscate its unique residential feature, which is considered as the birthplace for more sociocultural values that would further this aim. It is often stated that the potential of this feature empowers the Citadel to represent the place, acknowledging Erbil city through the global tourist milieus (Brammah 2009b, MacGinnis 2014), and this, according to Uzzell (1996), and Howard (2003), grants its built heritage substantial significance in global tourism. Therefore, the revitalisation's endeavour should be concentrated on how to devote a mechanism that assists in maintaining this feature foremost, not the opposite. This would largely maintain the Citadel as an historical influential incentive for the entire place within heritage tourism, which, in turn, may boost the definition of Erbil globally based on its cultural identity. In particular, the future trends to heritage tourism are increasingly seen as a leading incentive through which a new rapport can be found in the local-global nexus of the place based on the cultural potential of its historical environments, especially the ramifications that have begun to be felt between the economy and politics (Chhabra et al. 2003). Accordingly, quoting Park (2014), re-directing the potential of the Citadel towards global tourism perhaps 'serves both economic incentives and political principles' (Park 2014: 3).

However, the superficial methodology on motivation of such dimensions, sometimes, can drive to outcomes similar to the inconsiderate step of the evacuation, which has curbed the residential feature of the site, and thus its social constituents from serving as a keystone for such a trend in the revitalisation policy. 
The evacuation depicts the context as if it was rebuilt recently to accommodate completely new functions, which may expose the site's sociocultural potential, including its residential identity, to constant deterioration. Redirecting the site towards heritage tourism, despite the pursuit of political purposes, does not necessarily imply the elimination of the residential feature of this built heritage from its roots. If the Citadel's cultural context is powerful enough to flag the place's cultural significance globally, still its social constituents (which have tangibly contributed to its sociocultural potential) represent a concrete basis for evolution of this context over its deep history. Therefore, what empowers the context to acquire a universal status within heritage tourism is perhaps not its purely physical existence over six thousand years but rather its cultural layers amassed of 'experiences, histories, memories and thoughts' founded by its social constituents (Casey 2007: 507). Thus, if the Citadel's built context is a living cultural makeup that enables the re-displaying of the place, communicating its meanings and values globally, this should largely be a "surplus value" attributed to its local community as a popular institution that has its authority in shaping the cultural identity of the place. Embedded in this, their continuous interpretations of a stockpile of diverse sociocultural meanings and values, based on Smith (2006), can create a kind of place attachment for the visitor who consequently engages with a process of 'remembering' the place (Smith 2006: 2), which therefore solidifies its cultural identity globally. In the long-run, this can boost the economic incentives of the site.

This indeed makes heritage tourism goals of the Citadel 'integrated in the social fabric' of its urban context (Nicholas 2009: 397), 'as a determinant of residents' attitudes' (Uriely et al. 2003: 69). As such, the inhabitants' role in the industry of the Citadel's heritage attractions may create a "more harmonious relationship' between "conservation" and "tourism", and thus "economy" and "politics" as integral goals for the revitalisation policy (Aas et al. 2005: 37). This, on the other hand, may lead to the intact vision of making the revitalisation a selffunded process conditional upon the viability of the cultural map that will govern the site. It should therefore be inherent in the core of its authentic settings, while those local cultural assets should serve as a cornerstone of this map, which may increase visits and ultimately, economic returns. In both cases, Williams (2009) affirms that the inhabitants' role should be present in order to maintain an allencompassing oral display of meanings of these assets, as a 'socially produced... entity' mainly attributed to its social structure, thus keeping it responsive to the interpretations of the visitors (Williams 2009: 237). Otherwise, marketing this built context to heritage tourism as a rehabilitated physical structure may alter it into a raw material that fabricates the past for a global touristic consumption only. According to Samuel (1994), this often makes its cultural heritage 'a nomadic term, capricious enough to accommodate...discrepant meanings' narrated by outside visitors, and perhaps irrelevant to its history (Samuel (1994: 205).

In fact, this often leads to ostensible reconnaissance of these meanings, and thus superficial ties with them that result from an invalid access of some very local cultural assets of heritage. An example of this comes from Angkor heritage where its policies, drawn up through an imported approach, led to ignoring the site's 
anthropological accounts including oral history, local traditions and beliefs across generations (Jasim et al. 2017). Due to its incompatibility with the establishment of the site's cultural assets within heritage tourism, its policies have been reformulated according to a purely local-traditional approach. Linking this to Erbil, the revitalisation policy, citing Staiff et al. (2013), requires a rethinking of the tools 'used' in its 'heritage industry' before thinking of how the site be 'deployed' within heritage tourism (Staiff et al. 2013: 175). Thus, the intact policy to achieve both is perhaps through investing in its unique residential trait that grants it its outstanding universal value, and the inhabitants should be the first consideration of that, otherwise Erbil may soon face a similar fate to Babylon of being temporarily excluded from the WHL.

\section{Conclusion}

Planning for heritage sites' future policies should commence from their core potentials through which they are considered outstanding or unique in the world. The most appropriate driver for these potentials to start with is the elite that shares a long history with them, namely the site inhabitants. As the "key informant" of this, the latter can play varied roles in unveiling the diverse potential of built heritage and helping create a long-term growth for the planning of its future policies. Marginalisation of their contributions, in contrast, obfuscates revealing some cultural-historical facts inherent in the site's urban growth, which often drive to more transparent inputs, and thus more feasible outcomes regarding planning for cultural heritage-based tourism of the site. Erbil's chronological history, for instance, shows a variety of events and values since the Neolithic era until present, making local-based views an essential factor in boosting their display as a panoramic scene for the visitors. This, in turn, better contributes to a reliable process of uninterrupted re-creation of stories and meanings of the site through the visitor's ongoing narratives as part of an endless process of interpretations about these values and events.

However, what makes Erbil's revitalisation and renovation processes materially misstated is their non-insightful visions towards the potential of local engagement of its social constituents within their policies. Whilst the renovation attempted to perpetuate the residential feature of the site through resolving its urban relationship with the surroundings, its solutions collided with the site's local assets, thus failing to stop the continued departure of inhabitants, and adversely affecting this feature. The revitalisation plan, on the other hand, set this feature as a basis to initiate its tourism goals, but rather than seeking localbased efficient contributions to its revival, it soon totally abolished the value of this feature from the site's future policies, compelling the inhabitants to leave their homes. This has left the historical significance of the site mostly deactivated, as its cultural representation was distant from the concrete embedding of many sociocultural realities. This simply denotes the monotonic local approach within the revitalisation policy that has dominated many local conservation processes, which often privilege the site authorities over its inhabitants. The agglomerated 
sociocultural makeup over a long history of Erbil had to carefully be tailored with its future policies, due to its numerous sociocultural merits, which also entails engaging local-based views for more fruitful outcomes. Erbil's inhabitants are integral in the site's culture, history and meanings, which means granting them a position in displaying its cultural significance, as being the relevant knowledgeholders of its cultural roots. By contrast, their erasure as a living culture leads to challenging the reflexive understanding of visitors. Yet, the short-sighted vision of the value of these merits to the tourism goals has led to the marginalisation of these views, thus redisplaying the built context instead as rehabilitated architectural boxes that welcome any recreational activities that would bring investments and economic returns to the place.

Planning for cultural heritage landmarks, in this case, will not be based on an empirical vision originating from the site, but, mostly, on a kind of hypothetical practice, which might be according to what visitors' narratives dictate. This, deplorably, leads to a trivial access and ostensible exploration of some very local cultural assets of the site, particularly those ingrained in the roots of its social doctrines. As such, the Citadel's tourist aim should not be drawn to represent a charm of its physical assets, while the site's social accounts including local traditions and beliefs across generations are overlooked. This, indeed, entails rethinking how cultural tourism can be positioned within Erbil's heritage industry based on some potential that basically may originate from its local residential environment, making returning the inhabitants to the site essential. Particularly, keeping the site socially deserted can disavow the true embodiment of its cultural scenarios, deepening the gap between this aim and its real achievement on the ground. This perhaps was one of the problems that has prevented the aim from being achieved, which subsequently led the UNESCO Office/Iraq to appeal to any efforts that would really revive this aim and bring it back to life.

As a recommendation, further research should be conducted on the reasons that led to the marginalisation of the community role locally. If they were ingrained in the Iraqi laws of heritage conservation, it is important to investigate whether the roots of this may lie in the constitutionality of the laws' formulation. The mechanism of formulation of these laws with regard to the heritage's potentials and requirements should be revisited, focusing on the measures and determinants that have materially participated in constructing these laws. The latter should be upgraded with new tools and visions in accordance with what keeps them more flexible, comprehensive and open according to what may make them able to assimilate the diverse considerations surrounding the site. Embedded in this, the current revitalisation's guidelines of Erbil Citadel should sustain a state of flexibility connecting between its sociocultural hegemony and the politicalcultural image envisioned for the future of the site which invokes pride in the local history of Kurdistan. The guidelines should therefore aim at understanding the built context as a malleable notion that makes it possible to relate it to wider future tourism contexts, but tied to its authentic values and inner settings as a cultural and social makeup. Otherwise, altering the context from residential to touristic may subject it to a process of continuous building of non-fixed and 
fast-changing cultural entities, which may detach it from its traditional assets, and thus confiscate its historical-cultural identity forever.

\section{References}

Aas C, Ladkin A, Fletcher J (2005) Stakeholder collaboration and heritage management. Annals of Tourism Research 32 (1): 28-48.

Abu-Lughod JL (1987) The Islamic City: Historic myth, islamic essence, and contemporary relevance. International Journal of Middle East Studies 19(2): 155-176.

Assari A, Mahesh TM, Assari E (2012) Conservation of historic urban core in traditional Islamic culture: case study of Isfahan City. Indian Journal of Science and Technology 5(1): 1970-1976.

Avrami E, Mason R, Torre M (2000) Values and Heritage Conservation: research Report. The Getty Conservation Institute: Los Angeles.

Bornberg R, Tayfor M, Jaimes, M (2006) Traditional Versus a Global, International Style: Aarbil, Iraq. Available at: http://naerus.net/web/sat/workshops/2006papers/bornberg. pdf.

Bortolotto S, Zolese P, Lerici F (2013) Proposal for the Safeguarding of Cultural Heritage and Urban development: Theory and Methodology, Proceedings from First Internationasl Symposium on Urban Development. WIT Press, Koya

Brammah M (2009a) Revitalisation of Erbil Citadel-Iraq-Phase I, REF NO.: IRQ-EXT08-076, Final Report: Summary of Activities and Outputs of the Project; Brammah Huszar \& Associates: 67-68.

Brammah M (2009b) Revitalisation of Erbil Citadel -Iraq-, Phase I, REF NO.: IRQ-EXT08-076, Final Report: Implementation Action Plan; Brammah Huszar \& Associates: $22,26 \& 92$.

Casey E (2007) Boundary, place and event in the spatiality of the history. Rethiniking History 11(4): 507-512.

Chapman E (2008) Community, Heritage, Identity: Constructing, Performing and Consuming Welsh Identities in the US. Available at: http://theses.ncl.ac.uk/jspui/handle/10 443/529.

Chhabra D, Healy R, Sills E (2003) Staged authenticity and heritage tourism. Annals of Tourism Research 30(3): 702-19.

Crang M (1994) On the heritage trail: maps of and journeys to Olde Englande. Environment and Planning: Society and Space 12(3): 341-355.

Crooke E (2007) Museums, Communities and the Politics of Heitage Northern Ireland; In Museums in their Communities. London: Routledge.

Davis A (2009) Mediated reflexivity and the politics of politics. Journalism Studies 10 (2): 204-219.

Dicks B (2000) Heritage, Place and Community. Cardiff: University of Wales Press.

Dicks B (2003) Culture on Display: the production of contemporary visibility, maidenhead. Berks: Open University Press.

Din K (1993) Dialogue with the Hosts: An Educational Strategy towards Sustainable Tourism. In M Hitchcock, VT King, MJG Parnwell (eds) Tourism in South-East Asia. London: Routledge.

Ekurd (2017) Kurdistan's Erbil Citadel at risk of being removed from UNESCO World Heritage List. Retrieved from https://ekurd.net/erbil-citadel-risk-unesco-2017-01-21. [Accessed 09 August 2019]. 
GBTKRG (General Board of Tourism of the Kurdistan Regional Government) (2019) Statistics of tourist facilities in the Kurdistan Region (2019). Available at: https:// www.kurdistan24.net/en/news/a3bacb77-e8fb-40c6-8b94-7dc9933563a2.

HCECR (High Commission for Erbil Citadel Revitalization) (2008) www.erbilcitadel.org [Online]. Formal Website for the HCECR. Retrieved from http://www.erbilcitadel. org/index.php [Accessed 6 Oct 2019].

HCECR (High Commission for Erbil Citadel Revitalization) (2012a) Report on Erbil Citadel: Reinstatement of the Grand Gate.

HCECR (High Commission for Erbil Citadel Revitalization) (2012b) Report on Highlights of Erbil Citadel: History and Architecture: Visitor Guide.

HCECR (High Commission for Erbil Citadel Revitalization) (2012c) Final Report on Nomination of Erbil Citadel (Kurdistan Region, Iraq) for Inscription on the UNESCO World Heritage List; Vol. I.

Howard P (2003) Heritage, Management, Interpretation, Identity. London: Continuum.

Huang C, Jen R, Yang C (2012) Does world heritage list really induce more tourists? Evidence from Macau. Tourism Management 33(6): 1450-1457.

Huang YL (2006) Research on residents' attitude and perceptions on tourism impacts at chinese world heritage sites: a case study of Pingyao Ancient city. Journal of Guilin Institute of Tourism 17: 124-127.

ICOMOS (International Council on Monuments and Sites) (1999) The Burra Charter: The Australia ICOMOS Charter for Places of Cultural Significance.

ICOMOS (International Council on Monuments and Sites) (2002) Principles and Guidelines for Managing Tourism at Places of Cultural Heritage Significance. Retrieved from http://www.charts-inerreg4c.eu/app/download/5796628919/ICOMOS+Interna tional+Cultural+Tourism+Charter+1999.pdf. [Accessed 10 October 2019].

ICOMOS (International Council on Monuments and Sites) (2004) Principles for the Conservation of Heritage Sites in China. The Getty Conservation Institute. Retrieved from https://www.getty.edu/conservation/publications_resources/pdf_publications/ pdf/china_prin_heritage_sites.pdf. [Accessed 7 October 2019].

ICOMOS (International Council on Monuments and Sites) (2008) Quebec Declaration on the Preservation of the Spirit of the Place. Adopted at Quebec, Canada. Retrieved from https://whc.unesco.org/uploads/activites/documents/activity-646-2.pdf. [Accessed 8 October 2019].

ICOMOS (International Council on Monuments and Sites) (2011) The Paris Declaration on Heritage as a Driver of Development. Retrieved from https://www.icomos.org/Paris 2011/GA2011_Declaration_de_Parise_EN_20120109.pdf. [Accessed 11 October 2019].

ICOMOS (International Council on Monuments and Sites) (2013a) The Burra Charter: The Australia ICOMOS Charter for Places of Cultural Significance, 2013. Retrieved from https://australia.icomos.org/publications/charters/. [Accessed 9 October 2019].

ICOMOS (International Council on Monuments and Sites) (2013b) Understanding and Assessing Cultural Significance, Practice Note, Version 1, Australia ICOMOS. Retrieved from: https://www.scribd.com/document/306359089/Practice-Note-Unders tanding-and-Assessing-Cultural-Significance. [Accessed 7 October 2019].

ICOMOS (International Council on Monuments and Sites) (2014) Evaluations of Nominations of Cultural and Mixed Properties: ICOMOS Report for the World Heritage Committee 38th Ordinary Session, Doha, June 2014. 80-86. Retrieved from https:// whc.unesco.org/archive/2014/whc14-38com-inf8B1-en.pdf. [Accessed 5 October 2019].

Jasim MA, Hanks L, Borsi K (2017) Do really the audience's views efficiently boost built heritage conservation policies? Athens Journal of Tourism 4(4): 283-306. 
Jasim MA, Hanks L, Borsi K (2018) Repercussions of singularity of site authorities in making heritage conservation decisions: evidence from Iraq. Built Heritage 2(1): $77-$ 91.

Johnston A (2003) Self-determination: Exercising indigenous rights in tourism. In S Singh, DJ Timothy, KR Rowling (eds) Tourism in Destination Communities. Wallingford: CABI Publishing.

Jordan G (1990) Sub-governments, Policy Communities and Networks, refilling Old Bottles? Journal of Theoretical Politics 2(3): 319-332.

Kazimee BA (2010) Traditional Urbanism and Lessons for Global Cities: the Case of Isfahan, WIT Transactions on Ecology and the Environment, 128. Available at: www.witpress.com. ISSN 1743-3541 (on-line). Doi: 10.2495/ARC100121.

Kerr JS (2013) Conservation Plan: A guide to the Preparation of Conservation Plans for Places of Europe Cultural Significance, $7^{\text {th }}$ ed. Australia. Retrieved from https://aus tralia.icomos.org/wp-content/uploads/The-Conservation-Plan-7th-Edition-reducedfile-size.pdf. [Accessed 11 October 2019].

Macdonald R, Jolliffe L (2003) Cultural rural tourism: evidence from Canada. Annals of Tourism Research 30(2): 307-322.

Macginnis J (2014) A City from the Dawn of History: Erbil in the Cuneiform Sources. Publisher Oxbow Books. ISBN-13: 978-1782977971

Macginnis J (2009) Erbil is truly Unique: The Citadel of Erbil: an archaeological treasure. Cited in Brammah (2009a), p. 265

Mahmud S, Al-Naim M (2006) Reuse of Spaces and the Transformation of the Traditional Buildings to Accommodate Low-income Residence: A Case for Two Muslim Cities Dhaka and Hofuf, First Symposium of Charitable and Affordable Housing in Saudi Arabia; Khubar, April, 2006, p. 60-72.

Mahmud S (2007) Identity crisis due to transformation of home environment: the case for two muslim cities, Dhaka and Hofuf. METU JFA 24(2) 37-56.

Mitchell N (2008) Considering the authenticity of cultural landscape. In D Waite (ed) APT Bulletin, 25-32, xxxix (2-3). APT: Association for Preservation Technology International.

Naef P, Ploner J (2016) Tourism, conflict and contested heritage in former Yugoslavia. Journal of Tourism and Cultural Change 14(3): 181-188.

Nicholas LN (2009) Residents' Perspectives of a World Heritage Site. Annals of Tourism Research 36(3): 390-412.

Novacek K, Chabr T, Filipsky D, Janicek L, Vareka P (2008) Research of the Arbil Citadel, Iraqi Kurdistan, First Season. Pamatky Archeologicke 99: 259-302.

Park HY (2014) Heritage Tourism. London: Routledge.

Poria Y, Biran A (2006) Heritage site management: motivations and expectations. Annals of Tourism Research 33(1): 162-178.

Rico T (2017) The making of Islamic heritage: Muslim pasts and heritage presents, In R Trinidad (ed) Heritage Studies in The Muslim World. Palgrave: MacMillan.

Salazar NB (2010) The globalisation of heritage through tourism: balancing standarddisation and differentiation. In S Labadi, C Long (eds) Heritage and Globalisation 130-146. London: Routledge.

Samuel R (1994) Theatres of Memory, vol. 1: Past and Present in Contemporary Culture. London: Verso.

Silva K, Chapagain N (2013) Asian Heritage Management: Contexts, Concerns, and Prospects. Oxon: Routledge.

Smith L (2006) Uses of Heritage. Abingdon, Oxon: Routledge. 
Smith L (2012) 'Discourses of Heritage: implications for archaeological community practice'. Nuevo Mundo Mundos Nuevos/New Worlds New Worlds [online] Retrieved from http://nuevomundo.revues.org/64148. [Accessed 23 August 2019].

SOITM (Stiching Onderzoekscentrum Iraaks Turkmeense Mensenrechten) (2013) Erbil City. No. Art. 1-C0913 Iraqi Turkmen Human Rights Research Foundation: New York.

Southgate H (1840) Narrative of a Tour through Armenia, Kurdistan, Persia and Mesopotamia, vol. 2. New York: D. Appleton \& Co.

Su M, Li B (2012) Resource management at world heritage sites in China. Procedia Environmental Sciences 12(Part A): 293-297.

Staiff R, Bushell R, Watson S (2013) Heritage and Tourism: Place, Encounter, Engagement. London: Routledge.

Taylor K (2004) Cultural heritage management: a possible role for charters and principles in Asia. International Journal of Heritage Studies 10(5): 417-433.

Thapa B (2007) Issues and Challenges of World Heritage Sites in Nepal. In R White, J Carman (eds) World Heritage: Global Challenges and Local Sollutions, 23-27. Oxford: Archaeopress.

Timothy D (1999) Participatory planning: a view of tourism in Indonesia. Annals of Tourism Research 26(2): 371-391.

UNESCO (United Nations Educational, Scientific and Cultural Organization) (2005) Operational Guidelines for the Implementation of the World Heritage Convention (Paris: UNESCO World Heritage Centre). Retrieved from https://whc. unesco.org/arc hive/opguide05-en.pdf. [Accessed 11 Oct 2019].

UNESCO (United Nations Educational, Scientific and Cultural Organization) (2013) Report Published on the initiative "Engaging Local Communities in the Stewardship of World Heritage" (COMPACT). Retrieved from https://whc.unesco.org/en/news/ 1060. [Accessed 12 October 2019].

UNESCO (United Nations Educational, Scientific and Cultural Organization) (2014) Erbil Citadel Conservation Guidelines and Manual for Implementation, prepared by Ms. Patrizia Barucco and Ms. Lorenza Nicosia. 17-18

UNESCO (United Nations Educational, Scientific and Cultural Organization) (2015) Convention Concerning the Protection of the World Cultural and Natural Heritage. Bonn, Germany. Retrieved from https://whc.unesco.org/archive/2015/whc15-39com -19-en.pdf. [Accessed 12 October 2019].

UNESCO (United Nations Educational, Scientific and Cultural Organization) (2016) Contract for Individual Consultant: Request for Written Proposal. Cited in Jasim et al (2018) Repercussions of singularity of site authorities in making heritage conservation decisions: evidence from Iraq. Built Heritage 2(1): 85

Uriely N, Israeli A, Reichel A (2003) Religious identity and residents' attitudes toward heritage tourism development: the Case of Nazareth Heritage. Journal of Hospitality \& Tourism Research 27(1): 69-84.

Uzzell D (1996) Creating place identity through heritage interpretation. International Journal of Heritage Studies 1(4): 219-228.

Wager J (1995) Developing a strategy for the Angkor World Heritage Site. Tourism Management 16(7): 515-523.

Williams S (2009) Tourism Geography: A New Synthesis, 2nd ed. London: Routledge.

Wilson A (2003) All Parks are People's Parks. Policy Matters 12: 71-75.

Yang C, Lin H, Han C (2010) Analysis of international tourist arrivals in China: The role of world heritage sites. Tourism Management 31(6): 827-837. 



\title{
Developing Border Tourism in Sota, Merauke through Tourism Festival
}

\author{
By Machya Astuti Dewi ${ }^{*}$, Iva Rachmawati ${ }^{+}$Sri Issundari ${ }^{\ddagger}$ \& \\ Meilan Sugiarto ${ }^{\S}$
}

Studies on border tourism development mostly explore the role of government as an actor in developing border tourism. This study focuses on the government's efforts to promote border areas using festival tourism. Cross Border Tourism in Indonesia is still hindered by problems such as being located in remote areas and minimum public facilities, which impacts on the low number of visits. In order to attract more tourists, the Indonesian government through the Ministry of Tourism held Cross Border Festivals in a number of border areas in Indonesia, one of which is Merauke, the border area between Indonesia and Papua New Guinea. The current study analyzes the implication of Cross Border Festival for the economic development of the border area and the local communities in general. To do so, data was gathered from documentation study, field observation, and interviews with key persons and local communities in Sota, Merauke. The result of this study indicates that tourism festivals increase the number of tourist visits in border areas and the popularity of border areas, especially among domestic visitors.

Keywords: Cross Border Tourism, Community Awareness, Economic Impact, Merauke, Tourism Festival.

\section{Introduction}

Cross Border Tourism as a part of Special Interest Tourism (SIT), has been facing a classic problem: the location that is very far from the city center and the limited facilities, such as poor roadways and telecommunication. This has impacted on the tourists' visits. SIT alone started to develop in the early 1980s. SIT attracts a limited number of visitors. The consumers are those who travel not only because they want to have a good time, but also to fulfill their needs for experience, knowledge, or other spiritual needs. To attract more SIT visitors, the border areas need better facilities that could make it more appealing.

The border tourism that starts to grow in Indonesia has some similar problems. The distance from the city center and poor facilities hinder the

\footnotetext{
*Associate Professor \& Researcher, University of Pembangunan Nasional Veteran Yogyakarta, Indonesia.

${ }^{+}$Associate Professor \& Researcher, University of Pembangunan Nasional Veteran Yogyakarta, Indonesia.

*Assistant Professor \& Researcher, University of Pembangunan Nasional Veteran Yogyakarta, Indonesia.

${ }^{\S}$ Associate Professor \& Researcher, University of Pembangunan Nasional Veteran Yogyakarta, Indonesia.
} 
development. Even local people do not visit the borders. There are not many domestic tourists who are interested to visit border tourism. Many people believe that border areas are left behind and do not offer special things except the label of being a border. Borders such as between Indonesia and Malaysia, Indonesia and Papua New Guinea, and Indonesia or Timor Leste, have minimum public facilities. The recent construction of roadways, communications, and posts in the border area has given a positive impact on the Indonesian border area in recent years.

The Ministry of Tourism of Indonesia tried to boost border tourism by conducting a festival in 2016. The festival played an important role in the tourism industry both as an asset and a product of tourism (Cudny 2013). The main motivation for people to take a cultural trip is not only to have a good time but to get a new understanding and to experience something new. Holding festivals in the border area is expected to attract tourists who like cultural trips and SIT in general, cross border tourism in particular.

Cross Border Festival in Indonesia, managed by the Ministry of Tourism, offers music concerts, bazaar, cuisine and a number of sports events such as horse race and motocross. A huge number of tourists both domestic tourists and visitors from the neighboring country come to enjoy Cross Border Festivals. Cross Border Festivals in Atambua, East Nusa Tenggara, for example, could attract around 37,000 visitors in 2016. The visitors came from the domestic area and Timor Leste. Cross Border Festivals in Indonesia's border area to attract tourists is also conducted in West Kalimantan, Sanggau and Aruk, by importing artists from Jakarta. Besides that, they also showcase local culture in the form of dances, music, and cuisine. Cross Border Festival has been held since 2016 in Jayapura and Merauke. Just like other Cross Border Festivals, the one in Jayapura and Merauke are also aimed at increasing the tourists' visits.

This paper analyzes the impact of festival tourism on the local economy in border areas. Geographically, Indonesia's border areas are located in a remote area and they often lack infrastructure facilities. Whether or not the Cross Border Festival is able to boost economy and not just a fad is discussed in this paper.

\section{Literature Review}

Most studies on border tourism development emphasize the role of government as an actor in developing border tourism, both as the main actor or actor collaborating with other parties, including the private sector, communities, another state, or multinational corporations (Sotiriadis and Shen 2017). This study focuses on the government's efforts to promote border areas using festival tourism.

Getz (2008) locates festival tourism as a part of event tourism. According to Lord Cultural Resources Planning and Management, the festival is one form of event tourism that becomes a subpart of cultural tourism. Janiskee (1980) defines 'event' as a series of attractive and interesting activities that are held in a short period of time in a certain area to commemorate a specific happening. A study about special events as part of tourism management was started in 1970. The 
definition expands so an event is not only an important motivator or image creator of a certain area but also serves as the people's economic booster.

Event tourism could be classified into three groups, namely, events that refer to a cultural celebration, political activities, and art activities. The second group refers to all activities related to commercial, education, and science. The third group refers to sports, recreation, and other special activities. In other words, a festival is a part of cultural events tourism. Festival itself is an event that performs local culture from the non-material side (intangible product) like dances, music, customs, or local folktales. Holding events such as this could become a strategy to attract visitors and investors, become the main propeller for the tourism sector, and the main contributor in increasing the competitive advantage of a tourism resort (Getz 2008).

Meanwhile, Congcong (2014: 53) describes a festival in a more specific way. "It (festival) is a kind of social activity according to the needs of people living custom for a long time gradually established and passed from generation to generation". Therefore, festival tourism is an effort to construct tourism by utilizing the culture of local people.

".... is to promote the tourism development of the city and driving the economic development of relative industries, through the system planning, development and utilization of local unique cultural traditions, ethnic customs and characteristic industry, regularly or irregularly held in a particular area has a specific theme, set tourism, culture, economy, life as a whole, with extensive people to participate in the festival celebrations."

Congcong defines festival tourism through some preconditions. First, festival tourism offers local culture and customs and refers to a certain geographical area. Therefore, every festival in every region has its own uniqueness. Second, every tourist could participate and experience the event first hand. Third, culture, besides becoming the main commodity to attract visitors, also serves as a bridge for cultural communication among the citizens of the countries. Fourth, festival tourism is a very vast activity that includes local culture, local cuisine, lodgings, transportation, security, and political matters that are related to the policy and the administration of festival tourism. Last, festival tourism is a new form of tourism product that gives a different sensation to the tourists because they do not only experience different culture but they could also see it from a new perspective. Overall, a new product of cultural tourism industry ought to give not only a larger economic but also social impact.

Therefore, festival administration must have the element of culture in the form of tangible products as well as intangible products like dances and music. Although in reality, the administration of festivals as a part of tourism could not be defined merely as a local cultural product. As a product, in order to attract visitors, a festival is held in line with other local activities like sports events and contemporary music and arts. Festivals should not reduce the identity of the area. In fact, it should be able to create a brand that lasts. Cudny (2013) argues that the loss of local authenticity due to the intention to fulfill the tourists' demands could be the cause failure in a festival. 
Some academics believe that as a festival is held by the locals using local cultures and wisdom, then a festival could form the community bond itself. For Dunstan, as cited by Derret (2003), a festival could build a community. Organizing a big festival needs a great number of individuals and collective efforts. In order to prepare a festival, personal time allocation and kindness are also needed. With the joint activity, a festival could serve as a bridge to unite a community. In addition to this, a festival also creates a mutual social relation through the shared culture such as myths, folk stories, dances, and other traditional products that could spark pride in the local culture that motivates people to preserve it. In other words, festival functions as a medium of social cohesion strengthen local values and become an important token of difference (uniqueness) of place and community (Derret 2003).

Apart from how festival tourism is administered, Arcodia and Robb (2000) state that event tourism plays a big role in giving a significant contribution to the tourism industry because it could create various tourism demands like tours, lodging, and others so it gives socio-economic advantages for the surrounding community. A study by Stanskova and Vassenska (2015) reveals that local cultural festival shows a positive impact on the development of tourism because threefourths of the respondents of the study shows their specific interest to the local tradition and culture. The local tradition attracts local and foreign visitors. The study also claims that local festivals lead to economic advantage that has a direct impact on the economy such as increasing employment, business profits, and lodgings. Similarly, O'Sullivan and Jackson (2002) through their study believe that the impact of the festival does not only increase local people's income, but it is also able to strengthen the local community and raise life quality. In addition to this, the exploration history and local culture will also consolidate the local identity.

Scholars also believe that festivals bring positive impacts on the economy. Festival and event could significantly improve economic development and revitalization by rebranding tourism objects, increasing investments and promoting other economic activities of the area. A study by Gotham (2005) argues that Mardi Grass commoditization increases the level of consumption in New Orleans. Research by Prentice and Andersen (2003) shows that Edinburgh Festival returns the consumption level in Scotland. Research by Nagi and Nagi (2013) found that Sziget Festival and Budapest Parade are able to contribute to economic improvement in Hungary.

\section{Methodology}

This research uses a qualitative approach. The data was collected from field observation and interviews with authorities and local government staff, namely the Areal Secretary of Merauke Regency, The Head of Cultural Bureau, the Head of Tourism Bureau, and the staff of Industry Bureau of Merauke Regency. The interview also involved local people in the border area of Sota Merauke, especially with the souvenir makers and sellers. 
The collected data was analyzed by using analytic descriptive approach. The data is categorized based on specific issues, analyzed and interpreted. The findings were narrated and then concluded.

\section{Sota as Cross Border Tourism Destination}

Sota is a village that is located in Merauke district, Merauke Regency that has a direct border with Papua New Guinea (PNG) in the southern part of Papua Island, Indonesia. The village is located $80 \mathrm{~km}$ from Merauke. The roadway from Merauke regency to Sota is a good-asphalted road that passes through the forest and savanna of Wasur National Park. Sota itself is one of the tourism area owned by Merauke, other than Lampu Satu beach, Onggaya beach, Payum beach, Okaba beach, and Lotus Garden in Semangga.

Sota has one distinction as a unique tourism destination because it is a state's border area. It is located in the east end of Indonesia in the southern part of Papua Island. It has twin landmarks or the $0 \mathrm{~km}$ landmark like the one in Sabang, Aceh (the furthest west part of Indonesia, in the northern part of Sumatera Island). The other uniqueness of this area is the fact that traditional trades between Sota citizens, Weam, and Wereaber villages from Papua New Guinea (PNG) still exist. The traditional trade that depends on personal relations is done intensively on a regular basis. There were around 200-300 visitors from PNG and on average 100 people from Indonesia make visits to PNG every month ${ }^{1}$. The citizens of PNG who come to Sota usually shop daily needs like a noodle, sugar, coffee, clothes, and so on. On the other hand, they come to Sota with some items like venison, cassowary, and some simple farming tools. In recent years, the cross border traders from PNG start to sell lances, bags and other handicrafts as souvenirs that are managed by local citizens.

Besides having an advantage as an area that has a direct border with other countries and a traditional trade system, it is also located in the area of Wasur National Park that is so rich in flora and fauna. Sota also provides a unique phenomenon, that is, ants' nests or Musamus, something can only be found in Indonesia and a number of countries in Africa. In the border area between Indonesia and PNG, there is a park where tourists come to see the view or to spend their time on weekends. The number of visits to the border park is only high on weekends. Merauke regency does not have much modern entertainment such as cinema, theatre, or children's playground. People in Merauke go to natural places, like the border parks and beaches in the southern part of Merauke.

As a cross border tourism area, Sota is visited more by local tourists that come from Merauke or other regions like Jayapura. Visitors from outside of Papua or abroad come because they want to see Wasur National Park or because they have another business in Merauke. In other words, the border area of Sota has not been the main tourist resort in Merauke. The motivation to visit is merely to see the country's borderlines that cannot be found anywhere else in Indonesia.

\footnotetext{
${ }^{1}$ Pos Imigrasi Perbatasan Sota (2013) Merauke.
} 
A number of attempts have been done to increase the attraction of Sota as a tourism destination. Besides the border park, which was constructed by a local citizen, a project of ecotourism has been tried in the area for the first time. In 2013, Sota received aid for developing ecotourism in a 3-year project. Unfortunately, the 3 -year project was not successful due to the lack of awareness and participation of the community. From a number of interviews with local government officials, it is concluded that the main obstacle is from the community. The low awareness of the economic prospect of tourism makes the project sustainable for no more than 3 years, with central government's support. Lodgings that were newly constructed stalled and the fruits gardens for tourism destinations were not cultivated anymore. Out of three types of equipment of cajuput oil distillation, there was only one machine that was functional (Dewi and Rachmawati 2018).

The idea of ecotourism was started from the Merauke government's project to make Sota not only a cross border tourism object with its zero kilometer tower, but also to give the visitors a different experience in enjoying the natural attraction. Because the area is fertile land, they wish to make Sota an area that looks like Mekarsari Fruit Garden in West Java. Besides enjoying the view and fruits, the visitors could bring the fruits home (interview $18^{\text {th }}$ April 2017). Sota is a village that could produce up to 500 tons of fruits per year ${ }^{2}$. The main fruits are mangoes, oranges, pineapples, and bananas.

This failure is a lesson to learn for the government about what the community still needs. They need a bigger stimulus to be able to see the positive impact of the tourism industry to increase the local community's wellbeing. Generally, the local people do not have sufficient education and most of them work as farmers. Most people still rely on gathering from the surrounding forests. Therefore, to improve the economy through tourism, there should be an event that can invite more visitors to the border area through certain events; for example, based on the celebration of Indonesian Independence Day on August 17 that could attract hundreds of visitors either from Merauke or PNG, the ministry of Tourism of Republik Indonesia held Cross Border Festival. They expect that the cultural event could attract more tourists to the border area.

\section{Merauke Cross Border Festival}

The Ministry of Tourism of Republic Indonesia conducted Cross Border Festival in a number of areas in Indonesia's border area including Sota, Merauke. It is one of the efforts to increase tourism potency in border areas. The number of visitors that is significantly high is expected to increase the community's awareness of their economic potency. it is expected that the local people see the high number of visits as a way to open an economic opportunity. Vinsensius Jemadu, the Deputy Assistant of Asia Pacific Market Development of the Ministry of Tourism of Indonesia, stated that this activity is a strategy to attract foreign visitors, especially from Papua New Guinea. Besides, it is also expected to

\footnotetext{
${ }^{2}$ Biro Pusat Statistik (2015) Merauke dalam Angka 2014.
} 
increase the economic activities of the community in the border area so that the real sector could be improved.

Cross Border Festival is conducted in Merauke on August 17, 2016, and December 13, 2016, in Sota's field, Merauke, Papua. This event was dominated by band performances with a number of artists from the capital city such as Sandy Bethany and Black sound Dave Solution. They chose Reggae genre because according to the Head of Festival of the Deputy Assistant of Marketing Development of Asia Pacific, Adela Raung, the citizen of PNG likes Reggae music very much. This strategy seems to be successful to attract a big number of visitors from PNG to attend Cross Border Festival. Besides music shows, this activity also showcased local cultures such as dances, music, local cuisine, and local handicraft.

This event did not only improve the community's economic activities but also become media to foster good relations between countries (Gunawan 2019). Besides choosing the right music genre, the festival also shows the performance of a similar culture, cuisine, and it was also Visa-of-Visit-Free or Bebas Visa Kunjungan (Tribun 2016). The General Consulate of Republik Indonesia in PNG, Abraham Lebalauw, states that the local citizens of PNG really appreciate this event. It is very popular and could attract a number of PNG citizens to come.

\section{The Impact of Cross Border Festival}

The Ministry of Tourism of Indonesia noted that the festival was a great success with the high visit rate. There were 1,300 foreign tourists who came to Cross Border Festival on August $17^{\text {th }}, 2016$; and about 850 people came to the festival held on December $3^{\text {rd }}$, 2016. The data of Statistic Central Bureau "Merauke dalam Angka 2018" indicated the increase of tourists' visits in 2016, both domestic and foreign tourists (Figure 1). It is noted that in 2010 the number of tourists' visits was 303, it decreased to 110 in 2011, and continued to decline to 39 in 2012 and to 55 in 2013. There was an increasing number of 420 people in 2013 to 545 in 2015. A sharp increasing number happened in 2016 (1.720 tourists) but it declined again in 2017 (294 tourists). The same thing happened in 2016 when the Cross Border Festival 2016 was held. In the previous years the rate of domestic tourists' visits was only 9,000 in 2010-2013 and 37,432 in 2014 and 23,670 in 2015 , and 53,403 in 2016. Unfortunately, the tourist's arrival declined again in 2017 to 20,395 . 
Figure 1. Number of Tourists' Arrival in Merauke 2010-2017

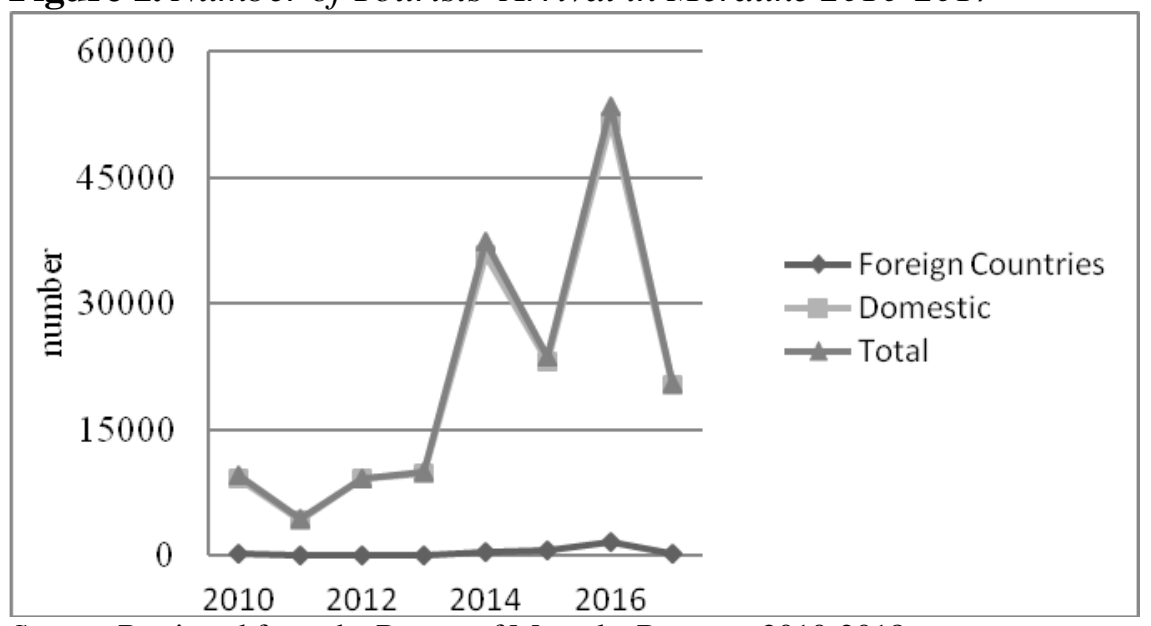

Source: Retrieved from the Report of Merauke Regency 2010-2018.

Not only that it increased the number of foreign and domestic tourist visits, the festival also increased the number of lodgings/hotels from 14 in 2016 to 18 in the number of rooms from 391 in 2015 to 495 in 2017 . This also increased the rate of employment in hospitality. Referring to the Ministry of Tourism of Indonesia, the increment of employment either direct or indirect in the tourism sector is how tourism contributes to the economy. The direct employment of tourism sector includes employment in accommodation, travel agents, airlines, and other passenger services including restaurants and recreational places that directly serve the tourists. The indirect employment includes in the sectors of promotion, furnishing, vehicle rentals, and transportation manufacturers, food and drink, wholesale, computer utilities, and personal services. An increase of tourism according to Bills Number 10 2009, there are 13 kinds of business field in the sectors of (1) tourism attraction, (2) tourism resort, (3) transportation service, (4) tour travel service, (5) food and drink service, (6) accommodation service, (7) management of entertainment and recreation, (8) gathering, incentive trip, conference, and exhibition organizer, (9) tourism information service; (10) tourism consultant service; (11) tourism guide service; (12) water tourism; and (13) spa. The number of lodgings increases from 194 in 2015 to 223 in 2017. In Merauke, there was an increase in the number of restaurants/cafés although they are not significant from 24 in 2015 to 27 in $2016^{3}$.

In the area of the Sota border, the number of economically capable persons because of cross border tourism was also significantly raised. Previously, there was only one person who owned a souvenir shop in the cross border area of Sota. Since the administration of the Cross Border Festival, there are many booths that are located only 10 meters from the zero points of the Indonesia-PNG border. The 20 booths are supported by one of the government's banks for empowering the border-area community. In the booths, local citizens sell cajuput oil, ants' nests, tshirts, hats, key chains, bracelets, sculptures, and noken bags. All of the items are local products, though still very simple in nature. The increasing number of sellers

${ }^{3}$ Biro Pusat Statisttik (2018) Merauke dalam Angka 2017. 
in the cross border area is considered as the influence of the Cross Border Festival that successfully attracts the tourists to visit Sota. An interview with a number of 'mama' (ladies) who sell souvenirs indicates that the number of sellers would increase if there is an event in the border.

The increasing number of visitors in the border area also motivates the local people to produce local souvenirs. Women work harder to produce more noken bags (noken is a traditional crochet bag made from wood fiber that is dried, spun, and ornamented with cassowary leathers). They can produce 5-7 noken bags if the raw material is available. The traditional bag production made by the skillful hands of Sota women is one of the promising businesses. They love the job because those bags are immediately sold (interview $26^{\text {th }}$ April 2018).

Similarly, the business of cajuput oil distillation that was activated through an ecotourism project is still maintained by the local people although the distillation machine that still runs well is only one. Surprisingly, from one unit machine, the people could produce cajuput oil that is sold as a unique product from Sota. Although they only reused energy drink bottles, the people's effort to produce cajuput oil as part of souvenirs in the border areas shows that the local people's enthusiasm starts to grow. Other products include wood sculpture and bone craft, key chains, bracelets, and other ornaments. The products that are not produced in Sota but sold in the booths are t-shirts and hats. Overall, the increasing number of booths has developed the tourism industry.

Besides souvenir booths, there are also food courts. Not far from the border park, there are 2 stalls that sell drinks and simple snacks. The food court is located 500 meters from the border milestone. The increase in food and drink booths and food stalls is not significant. However, this change is meaningful because it shows that people start to understand the economic potency of the area.

The positive impact of the event on the economic condition of the locals, referring to O'Sullivan and Jackson (2002), Arcodia and Robb (2000), is shown from the number of visits by tourists, the number of economic activities, or kinds of tourism economic activity bonds. In the case of Merauke, the positive impacts include raised awareness and the positive response of the local people towards cross border tourism. The impact of Cross Border Festival in 2016 is a real description that a border area is a potential area to increase the economy and wealth of the community. In other words, organizing a festival to attract visitors to come to the area has a positive impact on the local people's awareness and is able to motivate them to be more active in the tourism industry. Their pride in traditional products has increased as well.

Unfortunately, the Cross Border Festival did not continue in the following years. In 2017 and 2018, Cross Border Festival was only conducted in Skouw, Jayapura and Keerom Regency. In Keerom, Cross border Festival is held for three days. It was successful with 27,000 visitors (SUARAMERDEKA 2018). Meanwhile, in Skouw there were 5,000 visitors from PNG. Both areas are located on the border of Indonesia and PNG in the northern part that tends to be more populated and has better public facilities compared to the border of IndonesiaPNG in Sota, Merauke. The Cross border Festival is still organized with the same concept, which is attracting the tourists by inviting artists from the capital city and 
offering reggae music. Some local culture includes dances and local people's handcrafts.

The discontinuation of the Cross Border Festival decreased the tourists' arrivals as seen in Figure 1. This also influences the souvenir sales in the border area. The souvenir booths are full of sellers if there is an event in the border area but they will be empty if there is no event. The low number of visitors discourages the souvenir sellers in the border area. Some sellers admitted that the booths will be placed if there is an activity in the border area held by the local government of Merauke or a certain institution from Merauke regency (interview $26^{\text {th }}$ April 2018).

The Cross Border festival shows the dependency of the local community on a big cultural event held by the central government. The festival will promote more local products and local culture. A critic by West Kalimantan Forum on the Cross Border Festival mentions that the policy of the central government should be in agreement with the policy of regional government as part of development program starting from education sector, and vocational education and training for local community (Ramadhani 2017). Therefore, festival tourism could be conducted independently by the local community by using their own local culture by utilizing the available resources. The local community's skills and independence in administering an event in a border area still need a lot of external encouragement.

It is also important to conduct a discussion between the government of the Republic of Indonesia and the government of PNG to manage the border area. In the case of German-Czech borderland, Stoffelen et al. (2017) mentioned the importance of structural cross-border destination management with the multiscalar approach between the two countries in order to develop tourism destinations in the border area. It is a very good practice to be applied in the management of border tourism in Indonesia.

\section{Continue or Discontinue?}

The administration of a cultural festival could become a strategy for a tourism resort area to attract visitors. A cultural attraction that reflects the uniqueness would be branding for the region so it could attract more tourists to come. In some tourism destination areas, the festival has become the tourist destination itself like the Jember Fashion Festival in Jember. Every year, Jember Fashion Carnival attracts thousands of visitors and it yields extraordinary incomes for a number of business persons in the tourism industry. Meanwhile, Festival Penyu in Temajuk Kalimantan enjoys a great success by stopping turtles and turtle eggs hunting. Besides giving positive impacts like the increase of lodgings and restaurants, Festival Penyu or Turtle Festival in Temajok, West Kalimantan is able to conserve the nature and decrease the rate of turtle's deaths. The turtle festival is signed by releasing baby turtles to the sea.

The Cross Border Festival has improved the number of visitors in the border areas including Sota, Merauke. The music has become one of the main attractions, besides the performance of the artists from Jakarta and the BVK operation. The 
increased number of visitors has allowed local people to take advantage of providing food and souvenirs. The positive influence that is truly important from the administration of the Cross border Festival is not the increment in the number of stools and food courts, but in the local people's awareness about the economic potency that they have. This awareness has motivated them to produce a number of souvenirs such as noken bag, key chain, bracelet, necklace, carving, cajuput oil, and ants' nests.

A lesson to learn from the administration of the Cross Border Festival is that the dependency on central government is not good for the sustainability of the festival. Cross Border Festival is only administered twice and there are no other festivals. The people only serve as objects of the festival because they could not administer such an event on their own. This is against the spirit of the festival that should be promoting the identity of local culture and empowering the local people through the management of tourism potency. Besides the awareness of tourism potency, self-sufficiency should be nurtured by increasing the capability of the active people or the subjects of tourism industry.

\section{Conclusion}

Festival tourism is proven to be successful in increasing tourist visits in the border area. Developing border tourism through festival tourism in Indonesia has shown a similar trend. In the Papua region, which is known as a remote area and lack of visitors, attractions in festival tourism are magnets that encourage visitors to come. Thus, it is a positive impact on the tourism industry.

However, the participation of people in the border areas is not optimum yet. This is due to top-down planning. The idea of festival tourism comes from the central government. As a result, the packaging and the content of the festival tourism are not encouraging active participation of the border communities. The community becomes spectators, not being the actors in festival activities. The topdown nature also causes people to depend on the central government. The case of Sota, Merauke, shows that festival tourism is not a regular activity. The community is still dependent on the central government and local government initiation.

Thus the success of developing border tourism through festival tourism is largely determined by a good synergy between the government and the community. The government is still expected to be the initiator and provide the budget. To be sustainable, the community should take an active role in festival tourism. It is very important to open a discussion between the government and the community so that the festival of tourism in the border areas is no longer top-down in nature. 


\section{Acknowledgments}

Our thanks to the Ministry of Research and Higher Education of the Republic of Indonesia that provided funding for the research entitled "Community Empowerment through the Development of Border Tourism Area in Merauke". This article is part of this research.

\section{References}

Arcodia C, Robb A (2000) A future for event management: a taxonomy of event management terms. In Events beyond 2000: Setting the Agenda: Proceedings of Conference on Event Evaluation, Research and Education Sydney July 2000, J Allen, R Harris, LK Jago, AJ Veal (Eds), 154-160. Sydney: Australian Centre for Event Management.

Congcong T (2014) The study of festival tourism development of Shanghai. International Journal of Business and Social Science 5(4): 52-58.

Cudny W (2013) Festival tourism - The concept, key functions and dysfunctions in the context of tourism geography studies. Geographical Journal 65(2): 105-118.

Derret R (2003) Making sense of how festivals demonstrate a community's sense of place. Event Management 8(1): 49-58.

Dewi MA, Rachmawati I (2018) The barriers and strategy of Sota's border tourism area development. Masyarakat, Kebudayaan dan Politik 31(4): 400-409.

Getz D (2008) Event tourism: definition, evolution, and research. Tourism Management 29(3): 403-428.

Gotham KF (2005) Theorizing urban spectacles festivals. Tourism and the Transformation of Urban Space City 9(2): 225-245.

Gunawan MW (2019) Kemenpar: wonderful untuk perekat hubungan antar negara. [Ministry of Religion: wonderful for adhesive inter-country relations]. Tribun. Retrieved from: https://bit.ly/2YfToBo.

Janiskee R (1980) South Carolina's harvest festival: rural delights for day tripping urbanities. Journal of Cultural Geography 1(1): 96-104.

Nagi A, Nagi H (2013) The importance of festival tourism in the economic development of Hungary. Visegrad Journal on Bioeconomy and Sustainable Development 2(2): 57-59.

O'Sullivan D, Jackson M (2002) Festival tourism: a contributor to sustainable local economic development. Journal of Sustainable Tourism 10(4): 325-342.

Prentice R, Andersen V (2003) Festival as creative destination. Annals of Tourism Research 30(1): 7-30.

Ramadhani T (2017) Forum perbatasan kalbar sebut festival cross border Kemenpar tak bermanfaat bagi masyarakat. [West Kalimantan border forum call the Kemenpar cross border festival not beneficial to society]. Tribun. Retrieved from: https://bit. ly/34Ncj99.

Sotiriadis M, Shen S (2017) The contribution of partnership and branding to destination management in a globalized context: the case of the UNWTO Silk Road Programme. Journal of Tourism, Heritage \& Services Marketing 3(2): 8-16.

Stankova M, Vassenska I (2015) Raising cultural awareness of local traditions through festival. Tourism \& Management Studies 11(1): 120-127. 
Stoffelen A, Ioannides D, Vanneste D (2017) Obstacles to achieving cross-border tourism governance: a multi scalar approach focusing on the German - Czech borderlands. Annals of Tourism Research 64(May): 126-138.

Suaramerdeka (2018) Dibanjiri massa, festival cross border Keerom sukses besar. [Flooded by the crowds, the Keerom cross border festival was a great success]. Retrieved from: https://bit.ly/2ReWmEN.

Tribun (2016) Festival cross border Kemenpar sukses hebat di Merauke. [The Kemenpar cross border festival was a great success in Merauke]. Retrieved from: https://bit.ly/ 34RtW7K. 



\title{
Tourism Development in Rural Areas in Sweden - In the Shadow of a Well-Established Destination
}

\begin{abstract}
By Ulrich Schmudde ${ }^{*} \&$ Anna Sörensson ${ }^{ \pm}$
Tourism development has been studied by researchers for decades, yet the issue of destinations that are situated in the shadow of well-established destinations has not yet been addressed in any depth. This article defines these as destinations that exist in the shadow of a well-established place to visit with a strong identity and well-known brand. Well-established destinations with high profile branding attract many tourists. Destinations in their shadow, on the other hand, struggle with tourism and destination development. The aim of this paper is to better understand these types of destinations. The study is a multiple case study examining two shadow destinations located in rural settings in Sweden. Data were collected from semi-structured interviews with represent-tatives from the destinations' municipality, local destination development organisations, tourism companies, and infrastructure companies. Data were also collected from observations and written materials. The results show that shadow destinations could add value to tourists visiting well-established places to visit by offering attractions that benefit tourists. They also show the importance of destinations networking with each other and the usefulness of well-known brands in their communication with tourists. In addition, shadow destinations can help well-known places become more sustainable by reducing the pressure of unsustainable high numbers of tourists visiting them. Finally, shadow destinations could give tourists the option of choosing other tourist routes in a region, allowing them to experience attractions such as gastronomy routes, for example, in shadow destinations.
\end{abstract}

Keywords: Brand, Nature Based Tourism, Rural Destination, Shadow Destination, Tourism Development, Tourist Route, Travel Reason.

\section{Introduction}

Tourism development is a field that has been studied by researchers for decades (Saarinen, Rogerson and Hall, 2017; Shen, Morrison, Wu, Park, Li and Li, 2018). Kladou, Kavaratzis, Rigopoulou and Salonika (2017) discuss that tourism development in place despite if it is a country, a city or smaller place are extremely complex in nature. Tourists visit different destinations and in their minds they see that certain place as a "destination". One area that has received little attention from researchers is places that are situated close to high-profile nature-based tourism attractions. Hudman and Jackson (2003) argue that places that are situated near popular attractions are affected by the shadow effect. "The shadow effect refers to destinations that are near other major destinations. The

*PhD Student, Mid Sweden University, Sweden.

${ }^{ \pm}$Lecturer, Mid Sweden University, Sweden. 
concept comes from a geographic term "rain shadow". Some localities get less rain because the precipitation is diverted by mountains or wind patterns. Thus, one destination may be in the shadow of another destination, which is the preferred destination. Because they are close to the preferred destination, tourists will also visit the shadow destinations, but stay less time" (Hudman and Jackson 2003, p. 31).

Tourists that visit nature-based attractions might also want to experience other things in the nearby area. Tourists often see a destination as one unit, since it is a complex network that involves a large number of actors (Haugland, Ness, Grønseth and Aarstad, 2011). A destination can also be hard to determine geographically. Where does a destination start and finish, particularly in the mind of the tourists? The importance of treating the destination as a unit has resulted in a large amount of research focusing on issues related to destination development (ibid.). Destinations that are situated geographically close to a famous destination could benefit from the strong brand of the well-known destination. Ashton (2014, p. 279) argues that "brand is considered as a powerful instrument in creating a successful destination". Destinations with strong brands have a clear identity as well as image. Tourists feel recognition and therefore get the feeling of familiarity. Shadow destinations could therefore create relationships with famous destinations close to their area and benefit from their branding. Research has shown that one way of "moving" tourists beyond a specific tourist attraction to its surrounding areas is to develop different tourist routes, for example wine routes, scenic routes, or gastronomy routes. Gastronomy is of great importance to many tourists and is something that can convince tourists to take a detour to experience great local gastronomy while enjoying the scenery of the region and the destination. Shadow destinations can benefit from increased numbers of tourists visiting their region.

Research has not yet addressed to any great extent the issue of destinations that are situated in the shadow of a well-established destination. This article defines shadow destinations as places that exist in the shadow of a well-established destination with a strong, well-known, brand. These well-established destinations with famous brands and strong identities attract many tourists, while shadow destinations are home to struggling tourism industries and often experience stunted tourism development. The aim of this paper is to better understand destinations in the shadow of well-established places to visit.

RQ1: How is the tourism development of shadow destinations affected by their close proximity to well-established destinations?

RQ2: How can destinations in the shadow of well-established destinations benefit from the brand of the well-established destination?

RQ3: What kind of tourism development tools could shadow destinations use to develop tourism?

The structure of this paper is the following: the first section presents a literature review of research addressing areas such as travel reasons and tourism development, brand and identity, routes and gastronomy. In the second section, the study's methodology is presented. In the third section, the findings and discussion 
from the two cases are discussed and analysed. The fourth and final section presents the article's conclusions and implications.

\section{Tourism Development in Shadow Destinations}

\section{Reasons for Travelling and Tourism Development}

Tourism development is of great importance for many destinations around the world. In order for a destination to successfully develop tourism, it must be aware of tourists' travel reasons. Why do tourists want to come to their region and how can these travel reasons be addressed? Many researchers have argued that the views of the stakeholders as well as their involvement are key factors in gaining success (Andriotis, 2005; Byrd, Bosley, and Dronberger, 2009; Dabphet, Scott and Ruhanen, 2012; Ellis and Sheridan, 2014; Sánchez Cañizares, Castillo Canalejo and Núñez Tabales, 2016).

The natural environment and its resources such as mountains, lakes, rivers, forests and beaches are of great importance for tourism development concerning nature-based businesses (Lundberg and Fredman, 2012). Nowadays, nature-based tourism is a fast-growing industry in Europe. Fredman and Tyrväinen (2010) define nature-based tourism as tourism relying on a destination's natural environment as its key attraction. Tourism literature has, to a large extent, addressed the significance of nature-based tourism and its fast rate of growth in these regions as travel reasons (Lundberg and Fredman, 2012).

Travel reasons have their origin in psychology and are often discussed from a push and pull perspective (Baloglu and Uysal, 1996). Push factors are internal motives or forces that make tourists seek activities to fulfil their needs (Gnoth, 1997). Pull factors, on the other hand, are factors that attract tourists to a specific destination. During the development of modern psychology, push factors have been extended to "instincts", "drives", and "needs" (Gnoth, 1997; Tasci and Ko, 2017). Transferring these factors to travelling in general, they explain why people want to travel (Witt and Wright, 1992). "Pull factors", however, do not have their reasoning within people (Kliem, 2003). Instead, they are outside stimuli in the environment. People are attracted by what other destinations can offer them (Mundt, 2012). Pull factors influence the decision of where to travel in people who want to travel (Witt and Wright, 1992). Contrary to push factors, pull factors can be replaced (Kliem, 2003). For shadow destinations this means that there needs to be an awareness of the pull factors in different segments of tourists. Why do tourists want to come to their destination?

Since tourists' travelling habits change or simply because tourists might expect something extravagant at a simple level, creativity in suppliers is crucial (Leimgruber, 2017). Individual tourism actors, particularly those offering local niche products of agricultural land, play a significant role in the development. Leimgruber (2017) outlined the importance of cooperation and collaboration between tourism actors in his study of the local to the international level. Thus, there should be no narrow-minded locals, quite the opposite; they need to become 
creative when it comes to economic development (ibid.). For shadow destinations this may be crucial since they want tourists from the well-known destination to also visit them. Cooperation with the destination with a strong brand could also benefit that destination if it is overcrowded (Jacobsen, Iversen and Hem, 2019).

Tourist destinations do not exist on its own; it is part of a larger system, which often involve transport from the tourists' home to the destination. Several researchers has addressed this field (Butler, 1980; Prideaux, 2000) and the importance of how tourists travel to destinations. Leiper (1990) showed the notion of a transit route region through which departing and returning travellers pass during the course of their travel. These destinations exist due to other destinations that is the key attraction for the tourists. Hudman and Jackson (2003) argue that places that are situated near popular attractions are affected by the shadow effect. "The shadow effect refers to destinations that are near other major destinations. The concept comes from a geographic term "rain shadow" (Hudman and Jackson 2003, p. 31). Some localities get less rain because the precipitation is diverted by mountains or wind patterns. Thus, one destination may be in the shadow of another destination, which is the preferred destination. Because they are close to the preferred destination, tourists will also visit the shadow destinations, but stay less time" (ibid.). These shadow destinations need to find a way to create its own brand and identity to attract the tourists that are travelling pass its place.

\section{Brand and Identity}

Nowadays, the importance of branding for successful destinations is well known to researchers (Ashworth and Kavaratzis, 2009; Govers and Go, 2009; Kladou, Kavaratzis, Rigopoulou and Salonika, 2017). Shadow destinations might need to build their own brand as well as use the benefits of the well-known brand (e.g. destination) that it is in the shadow of. Building strong brands is closely related to brand identity as well as brand image and brand personality. Companies that sell products and to some extent services have been previously studied but more research is needed in this area for the tourism industry. "When creating brand image for a tourist destination, the iconic features of the destination must be brought up and created in the tourist's mind" (Ashton, 2014, p. 285). Ashton (2014) argues that destination branding is based on the destination's environment and resources. Firstly, to build a successful destination the destination must develop a strong brand identity and a brand image which successful destinations seem to have (Aaker, 2010; Qu, Kim and Im, 2011). The risk of having a weak brand is that the brand will not be memorable and will not create recognition in the tourists' minds, which is of great importance since it creates familiarity with the brand (Aaker, 2010). Qu, Kim and Im (2011) argue that brand loyalty, the perceived quality, and the associations the tourists have towards a brand build up a strong brand. The perceived quality of a destination with a strong brand can result in an association of a high-quality service, which in turn will lead to loyalty and create more awareness of the brand. Furthermore, this may result in a broader recognition and lead to increased brand awareness. 
Tourists often associate a brand with certain features and it is therefore important that "iconic features of the destination must be created in the tourists' mind" (Ashton, 2014, p. 284) to deepen the awareness and create associations that cross tourists' minds every time they are in contact with the brand. "A brand's value proposition is a statement of the functional, emotional [and] self-expressive benefits delivered by the brand that provides value to the customer" (Aaker, 2010, p. 95), which will create a relationship between the brand and the tourist. To develop these feelings towards a destination and its brand, tourists must know what the place is actually offering and the communication of functional attributes and emotional benefits is quite important to keep uniqueness and authenticity (Insch, 2011). Shadow destinations or unsuccessful destinations often lack a clear identity for the tourists. Tourists that identify with the values will fulfil their interest and create an emotional involvement, which will consequentially lead to loyalty towards the brand and to the destination. Insch (2011) states that surroundings are the core aspect of a brand's image and the motivational factor for a destination.

Keller (2016) argue that brand extension may be useful when there exist an established brand name and this brand can be used in new products and service. This may be useful for shadow destinations that exists closely to destinations with a strong brand. The brand can help tourists to find their way to the shadow destinations.

\section{Tourist Routes}

One way to convince tourists to travel beyond famous destinations and visit shadow destinations is to use routes of different kinds, such as scenic routes or gastronomy routes. The route concept is often considered to be an effective method of tourism distribution (Meyer, 2004). Route tourism means that a series of attractions are linked together in order to promote local tourism and encourage tourists to travel from one place to another. Routes may vary in length and some of the best and most successful rural routes feature wine or gastronomy with examples of these found all over the world (Bregoli, Hingley, Del Chiappa and Sodano, 2016; Andersson, Mossberg and Therkelsen, 2017). Linking a number of smaller providers together means they can be marketed collectively as "one" tourism destination or attraction. Lourens (2007) argues that the successful development of tourism routes is not an exact science and developing destinations often have difficulties to overcome. Research often uses terms such as themed routes, trails, and scenic by-ways (Meyer, 2004; Lourens, 2007). Trails usually refer to short distances and involve tourists visiting attractions by foot, bicycle, or horse riding, while routes and by-ways usually refer to driving.

Another concept is rural trails or heritage routes that aim to promote rural tourism. Themed routes can encourage tourists to take a detour through rural areas and to shadow destinations. They provide a good opportunity for less-developed areas to use cultural resources to attract more tourists. When developing these routes, it is of great importance to know the tourists' needs and reasons for 
travelling along the route. It may also differ if they see the route as a destination in itself or just a way to reach their final destination.

Lourens (2007) states that it is important to identify critical success factors. Firstly, the conceptualisation of the route must be based on market research that identifies key target markets (key segments) and their requirements. This research should be conducted on an ongoing basis to ensure that the latest tourism trends are taken into account. Secondly, an investigation must be conducted in the area to map what tourism products can be offered. What is the clear minimum standard for tourism operators? Otherwise, the results may cause a huge effect on the entire route. Thirdly, what are the tourism assets and unique selling points of this area and its products (Briedenhann and Wickens, 2004)? A macro-level strategic plan should be conducted to state how tourism development should be carried out in this area. Fourthly, the size of the potential membership base should be decided on. Operators along the route should be included early on in this process so they can together find the unique features and main themes of the route. The route should include diversification and a suitable mix of products for the area. Fifthly, a clear brand identity for the area must be established, which is important for shadow destinations. Marketing is of great importance and the area's identity should be determined by its unique selling points. At the same time, it is very important not to overstate the attractions of the destination (as the consequences of this would be to under-deliver). Sixthly, the route must put together a clear strategy of day-to-day operations. Finally, a financial plan should be put in place. In the early phases, resources are needed to create the "route" (see the steps above). It needs to be remembered that this is a long-term commitment that often takes time to mature. Many routes start on a very small scale and it can take up to 30 years to deliver significant economic results. Therefore, long-term goal setting is important, and working from a short-term perspective should be avoided (Lourens, 2007).

Briedenhann and Wickens (2004) argue that if tourists are distributed along a route, the negative environmental impacts of tourism are reduced and economic benefits are more evenly distributed. The development of rural tourism routes and the clustering of activities and attractions also foster cooperation and partnerships between tourism companies (ibid.). Pikkemaat (2012) clearly outlined that the tourism companies often prefer to ask for the "what" instead of the "why" concerning the implementation of new ideas. Thus, the route must be conceptualised based on solid market research, which identifies key target markets and their requirements (Lourens, 2007).

\section{Gastronomy}

Tourism development and reasons for travelling are often strongly intertwined with gastronomy and its importance for tourists. Kivela and Crotts (2005, p. 51) argue that "gastronomy is inextricably linked to the destination and the destination's image; maybe in multidimensional form [...]. Importantly, the study confirms that gastronomy tourism is a meaningful and possibly a highly loyal 
market segment. It can also be hypothesised that gastronomy experiences are powerful tools for marketing the destination".

In Northern Europe local gastronomy in general is seen as part of the heritage of a region, and it plays a significant role in developing rural tourism nowadays. These products can be new, traditional, or based on specific food conceptions (Vitters $\varnothing$ and Amilien, 2011). In Sweden, local food products have also become a very important tool in developing local tourism, more so than national tourism (Sörensson, Dalborg and Bogren, 2016). The Swedish organisation "VisitSweden" states that gastronomy is one of the three major pillars in Swedish sustainable tourism development (VisitSweden, 2018). According to VisitSweden, 95 percent of tourists say that they want to have a unique food experience during their travels, and already 8 percent of tourists claim that food and experiences are their main purpose for a holiday in Sweden (Sörensson, Dalborg and Bogren, 2016). Moreover, local cuisine has the ability to enhance the visitor experience by connecting tourists to the region and its perceived culture and heritage (Sims, 2009). A food tourist may be defined as a person who selects travel destinations mainly due to anticipated food experiences and who therefore seeks out food, meals and food-related activities offered at the destination. The types of experiences gained from consuming food on holidays seem to vary and may for instance cover sensory, cultural, and social experiences (Andersson, Mossberg and Therkelsen, 2017). Furthermore, tourists are often sometimes food tourists while few, if any, are food tourists all the time (Getz, Robinson, Andersson and Vujicic, 2014). Taken together, this adds a further level of complexity to food tourism demands.

\section{Methodology}

The present study was constructed as a multiple case study where two shadow destinations in a rural setting in the middle of Sweden were chosen. The study had a qualitative approach with an abductive approach (Järvensivu and Törnroos, 2010). These destinations are situated at the same latitude but in two adjacent counties in Sweden. The geographical context of the destinations is presented later in this section. Data were mainly collected from semi-structured interviews with representatives from local municipalities, destination marketing organisations (DMOs), tourism companies, and infrastructure companies.

The interview guide focused around four themes; tourism development in shadow and well-established destination, brand and identity, tourist routes, and gastronomy. Examples of questions that were asked to the respondents are given in Table 1. 
Table 1. Examples of Questions

\begin{tabular}{|c|c|}
\hline Themes & Interview questions (examples) \\
\hline $\begin{array}{l}\text { Tourism development of } \\
\text { shadow and well-established destination }\end{array}$ & $\begin{array}{l}\text { How can the destination develop further? } \\
\text { What is needed for the destination to } \\
\text { develop? } \\
\text { How is the destination influenced by the } \\
\text { other attractions in the area? } \\
\text { What can the destination do in order to } \\
\text { create an even more attractive destination? }\end{array}$ \\
\hline Brand and identity & $\begin{array}{l}\text { What are the key attractions in the region? } \\
\text { What is the destination/region known for? } \\
\text { What are the key travel reasons for the } \\
\text { destination (from the tourists' perspective)? }\end{array}$ \\
\hline Tourist routes & $\begin{array}{l}\text { How do tourists travel to and in the region? } \\
\text { How can the travel in the region become a } \\
\text { travel reason? }\end{array}$ \\
\hline Gastronomy & $\begin{array}{l}\text { What is the role of gastronomy for tourism } \\
\text { development? } \\
\text { What are key gastronomy attractions in the } \\
\text { region? }\end{array}$ \\
\hline
\end{tabular}

A total of 14 respondents were interviewed and in some cases two interviews were conducted with the same representative. Data were also collected from observations and written materials. Data were analysed using interpretative analysis involving the construction of themes. The analysis is based on four themes (as described above) namely reasons for travelling and tourism development (1), brand and identity (2), tourist routes (3), and gastronomy (4).

\section{The Case of Västernorrland County and Härnösand}

Västernorrland County is situated in the middle of Sweden and borders Jämtland, Västerbotten, and Gävleborg Counties and the Gulf of Bothnia on the Baltic Sea. It has an area of 21,685 $\mathrm{km}^{2}$ and is the sixth largest county in Sweden, home to approximately five percent of Sweden's population. It consists of seven municipalities. Härnösand is a small city with a population of approximately 18,000 , with a total of 25,000 in the entire municipality. The city of Härnösand was founded in 1585 by King Johan III and it is the county capital of Västernorrland.

The largest and most well-known tourist attraction in Västernorrland County is the UNESCO High Coast World Heritage Site. The High Coast is the world's highest coastline and is home to the world's most dramatic land uplift since the inland ice retreated over 10,000 years ago. The land uplift world record has been measured at the top of Skuleberget, where the ancient coastline is presently an impressive 286 metres above sea level (The High Coast, 2019). "These natural phenomena are unique on earth and evidence of the amazing land uplift experienced in the area after each Ice Age. The area is also home to Sweden's highest island, Mjältön, that juts 236 metres out of the sea, and the Baltic Sea's deepest point, Ulvödjupet, which measures 293 metres deep" (ibid.). The High 
Coast is the largest tourism attraction in the county and had approximately 542,000 guest nights in 2017.

The city of Härnösand is situated $23 \mathrm{~km}$ south of the High Coast region along the E4 highway. Many tourists pass the city on their way to the High Coast, but few stop in Härnösand despite the city having several tourist attractions. The city is the county capital (despite it being smaller than both Sundsvall and Örnsköldsvik) and is therefore home to several museums including car, boat, and county museums. Härnösand is a small, pleasant city surrounded by water and it has been selected as Sweden's second-best summer town (ibid.).

\section{The Case of Jämtland County and Östersund}

Jämtland County is situated in the middle of Sweden and borders Norway and the counties of Dalarna, Västerbotten, Gävleborg and Västernorrland. It covers 12 percent of Sweden's area but only 1.5 percent of Sweden's inhabitants live there. It consists of 8 municipalities and is one of Sweden's largest tourist destinations. With the exception of Gotland, Jämtland County is the least industrialised county in Sweden, with only 15 percent of the population actively working in industry. Industry in Jämtland is dominated by small businesses, with only 50-60 of the county's industrial companies having over 50 employees. Östersund is the main city in the county, with a population of approximately 51,000 inhabitants living in the city and 63,000 in Östersund municipality (Statistiska Centralbyrån, 2018). The city of Östersund was founded in 1786 by King Gustav III and is the county capital.

Figure 1. Map Over the two Destinations and their Proximity (Own Creation)

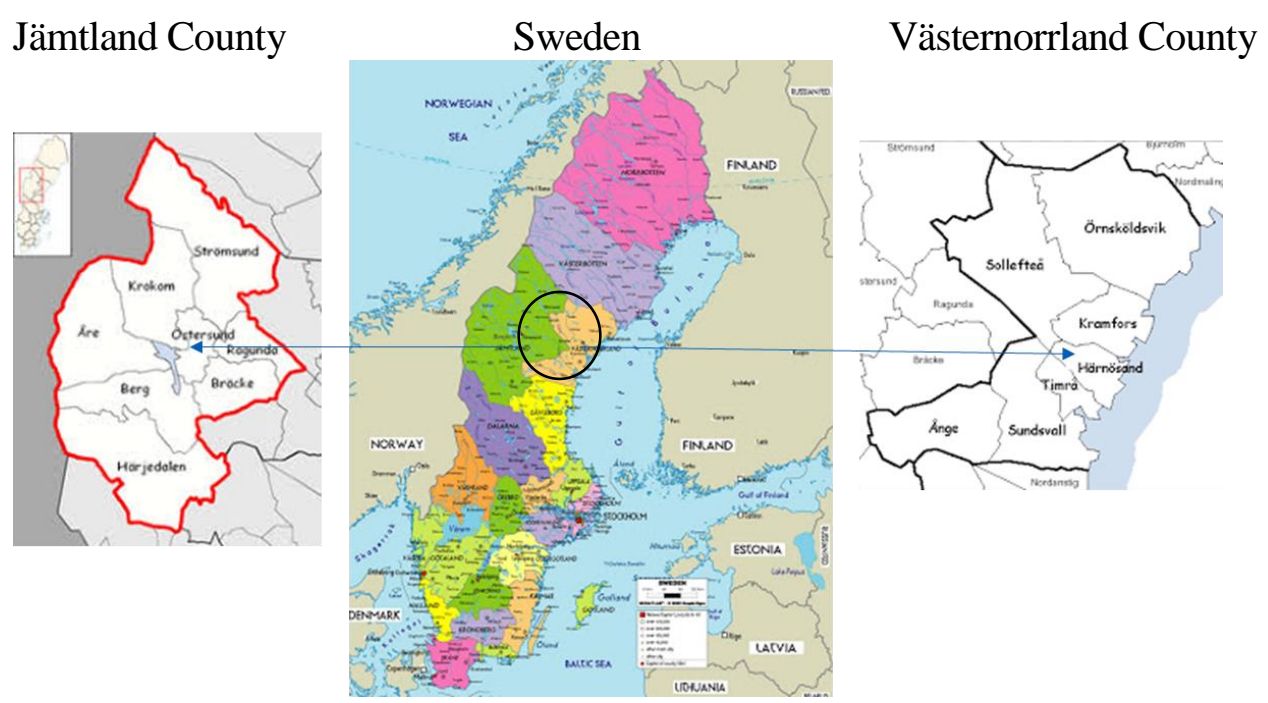

Östersund is situated by Sweden's fourth largest lake (Lake Storsjön). The county is primarily known for a number of large ski resorts, such as Åre, which are well known by both Swedish and international tourists. Östersund is situated 
approximately $100 \mathrm{~km}$ east from Åre. The airport situated just outside Östersund, on the island Frösön, is named Åre/Östersund Airport, which indicates the importance of the nearby ski resort. Östersund is known as the "Winter City" due to hosting several winter events, including World Cup Biathlon competitions. It is also home to Sweden's oldest music festival, "Storsjöyran".

This figure above gives an overview over the studied counties and their location.

\section{Findings and Discussion}

\section{Travel Reasons and Tourism Development in Härnösand and Östersund}

The tourism industry in the entire county consists primarily of small and medium-sized tourism companies. The county does not have a large number of small tourism companies but rather more well-established attractions such as Hemsö Fortress, the High Coast Distillery, and Hernö Gin. The target market of the High Coast is mainly Swedes, Norwegians, Germans, and Dutch (Statistiska Centralbyrån, 2018). There are also specific markets such as tourists travelling on cruise ships (Birka Cruises, 2019), which bring about 13,000 tourists to the area annually. The main attraction of the High Coast is the unique nature experiences it offers (The High Coast, 2019). Tourists do not mainly come to Härnösand for shopping (as they do to Östersund which is described further down). The largest city in the county, Sundsvall, is the shopping centre for the county. Outside of Härnösand the largest tourists attraction exist which is an outlet for Fjällräven which is a well-known outdoor brand famous for their iconic backpacks. Härnösand can offer a well-known beach of Smitingen that attracts tourists that want to lay on the beach and take a swim in the sea. There is also a bath house but it does not attract a larger amount of tourists. There are plans for Smitinge to build a camping in a nearby future.

There are several events that also attracts tourists like the music festival of Stadsfesten. Another event is the car cruising during the summer. Many of the larger events occur during the summer and Härnösand would like to attract tourists other times during the year (e.g. low seasons). Both Hernö Gin as well as The High Coast Distillery do not only sell high quality products but are also nowadays large tourist attractions. These distilleries have expanded during the last years and do also offer tourists different events during the entire year. Most of the tourists come by car or train to the region. There also exists an airport in the nearby area of Härnösand which is called Sundsvall/Timrå Airport.

The main tourist targets for Östersund are Swedes and Norwegians. Östersund had around 458,000 guest nights in 2018 (Jämtland/Härjedalen Turism, 2018). Östersund's tourism attractions include nature and adventure activities but shopping is also of great importance to the city. Östersund is a well-established trade city because it is the only sizable city in Jämtland County and it has been a tradition among people to combine their visits to Östersund with shopping. A large number of Norwegians travel over the Swedish border to Östersund to take 
advantage of the lower prices on food and other products in Sweden. It seems that Norwegians have a strong push effect where shopping in Östersund is concerned (Gnoth, 1997).

Östersund is home to a large commercial shopping centre, Lillänge, located on the outskirts of the city as well as shopping in the city centre. Lillänge opened its doors in 2004 and is not considered a competitor to the city centre, but rather a complement as it encourages Norwegians and people from the entire county to come to Östersund to shop. Of course, many of these visitors also visit the city centre and stay overnight or over the weekend. Lillänge is primarily home to stores belonging to large, well-established retail chains.

The swimming pool Storsjöbadet and Frösö Zoo are not enough to attract Norwegians to visit Östersund. The zoo in particular is experiencing decreasing interest due to environmental and ethical concerns. The question is: if the zoo disappears, what attractions can Östersund offer then? Norway does not allow zoos, which makes them an attraction in Sweden. Big events such as soccer festivals, music festivals, and Biathlon world cup competitions contribute towards tourism development in the city, which tries to create events that will attract tourists who would otherwise not visit Östersund, and the pull effect is a strong factor in this (Witt and Wright, 1992).

Transportation to the destination has its own role when it comes to tourism development in Östersund. Air, rail, and road are the accessible transportation possibilities. Direct flights run between Östersund and several destinations in England (e.g. London Gatwick and Bristol) during winter season, which has led to an increasing number of British tourists in Åre, but this has not been seen as strongly in Östersund. The same is fact during the winter seasonal direct flights between Östersund and Copenhagen (DK) as well as Östersund and St. Petersburg (RU).

\section{Härnösand's and Östersund's Brand Identity}

Härnösand does not have a clear, strongly established individual identity. The results of this study indicate that its identity is strongly intertwined with the identity of the High Coast. It is the attraction of the region that is communicated and the value of the brand is what Härnösand is partially communicating. The municipality of Härnösand stated that "We want Härnösand to be recognised as part of the High Coast - the sea, the wind and the waves" ${ }^{1}$ (Härnösand, 2019). Härnösand also uses the "harbour" as an important brand icon for the city. The harbour should help label Härnösand as a shipbuilding town, which it was years ago as well as today and this has symbolic value - as it represents being well received and feeling safe and secure. The logo for the city of Härnösand is therefore a wave. The city of Härnösand uses the High Coast branding in its own branding (see Figure 2 below). Ashton (2014) argues that a destination's environment and resources should be illustrated in the brand. Härnösand clearly uses the value of the High Coast brand and strongly identities itself with that area.

${ }^{1}$ Free translation from Swedish to English by the authors "Vi vill att Härnösand ska förknippas med Höga kusten - havet, vinden och vågorna." 
Insch (2011) discussed the importance of a destination's surroundings and Härnösand has incorporated this into their logotype with an ocean wave.

Figure 2. The Brand of Härnösand

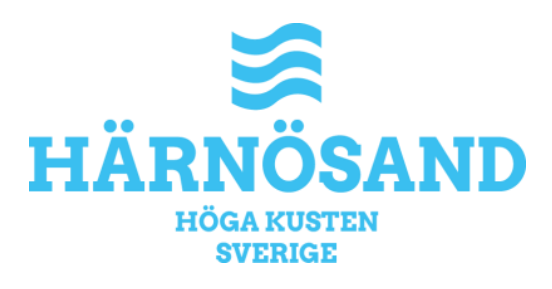

Östersund's brand and identity is based on a snowflake shaped like a heart. The logo was designed in 2007 for the Biathlon World Championship 2008 and has been used to market Östersund ever since. Summer tourism in Östersund is more established than winter tourism and the brand uses an intentionally wintery logo in order to encourage tourists to visit the city in the winter as well, with the aim of achieving economic growth in the tourism industry during the colder months of the year. During this time of year, Östersund is in the shadow of top winter destinations such as Åre, Vemdalen, and Funäsdalen, which are all located in Jämtland County. These destinations are fully established winter tourism hotspots, in particular the ski resort of Åre.

The branding and logo for Östersund was the subject of an ongoing discussion in 2017-2018, which resulted in the decision to keep the snowflake heart, but it will now be altered according to the season. After the snowflake heart was introduced, research on the effects of the brand was conducted. The results showed that it has become a positive and well-known symbol for Östersund that is recognised both nationally and internationally. Earlier, a rainbow heart was used and during the UNESCO gastronomy conference in 2016 a heart with cutlery was used. In general, the city has kept the heart as a foundation for its marketing, with marketing campaigns being adapted to suit events being held in Östersund. Östersund uses the snowflake heart as its own unique brand and actively associates itself with its neighbouring high-profile ski resorts, in particular Åre. The snowflake heart is unique for the area and keeps it iconic features, even if it is altered for different events, which is a factor named as important by Ashton (2014). 
Figure 3. The Brand of Östersund

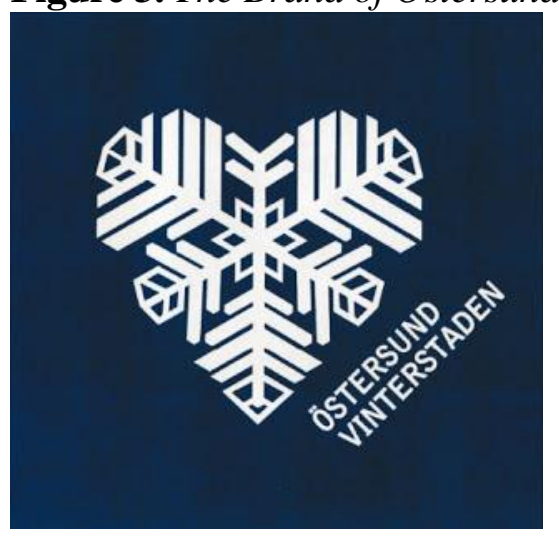

\section{Tourist Routes}

Both Härnösand and Östersund have a limited number of tourist routes in their immediate surrounds. The High Coast is mentioned in marketing material issued by camping.se as one of five "routes worth a detour". This could serve as an example for the Härnösand area where new routes could be established to attract tourists to explore beyond the High Coast area. Currently, Härnösand is not on the High Coast route.

Östersund has several small routes based on different points of interest such as searching for the great lake monster and a $25 \mathrm{~km}$ long Skärgårdsvägen (archipelago route), which starts in the centre of Östersund and takes the visitors via a bridge to the island of Andersön and then via a free-of-charge ferry to the island of Norderön. From there they can continue via another ferry to Håkansta. This is a cultural route that combines history and local food experiences in a picturesque natural setting (Skärgårdsvägen, 2019). Another route is the Snilleriket (the kingdom of geniuses), which is a local route that combines travelling, local food experiences, and local living (Snilleriket, 2019). This route is located in the neighbouring municipality, but it combines well with Skärgårdsvägen.

\section{Gastronomy}

In the Härnösand area there is a small number of well-established gastronomy entrepreneurs. Examples include Hernö Gin and the High Coast Distillery, which are among the most famous alcohol producers in Sweden. The area is also home to a number of microbreweries operating on a smaller scale. Both Hernö Gin and the High Coast Distillery organise different tourist events such as festivals, guided onsite tours, and tastings. They have expanded in recent years due to increased demand. The area is also home to a bakery and a cheesery that are popular among tourists.

In Östersund, and Jämtland County, gastronomy companies are more prolific. A larger amount of small-scale entrepreneurs that produce different products are in business, often working in their free time, on a part-time basis, or as sole proprietors. There are also a number of companies that act as employers in the gastronomy sector. In 2012, Östersund was named Food Capital of Sweden so the 
city has become well recognised for its local food and food production. It is a member of the UNESCO Creative Cities Network (UCNN), and, together with Norrköping, it is one of only two Swedish cities in the network, and the only Swedish city in the gastronomy network, whose members include 26 cities from around the world. One of the reasons why Östersund was appointed is the purposeful work within small-scale food crafts and the connection to culture, gastronomy, and tourism seen in the area (UNESCO, 2019; Östersund, 2019; Visit Östersund, 2019). In 2016, the global network held its annual meeting in Östersund with over 250 delegates attending, to experience a gastronomic and cultural week and take part in the international research conference. The annual meeting was a success and the city was awarded with the Swedish UNESCO Prize in 2017 (UNESCO, 2017).

The products on offer in the city go far beyond the examples given here, Östersund and Jämtland County are well known for culinary experiences featuring primarily locally produced foods. In central Östersund alone, three restaurants have been nominated for "White Guide" awards for best restaurant/café in Sweden (White Guide, 2019).

\section{Theoretical Contribution from this Study}

The theoretical contribution made by this study is that smaller cities that are situated in close geographical proximity to a well-known destination with a strong brand can be called shadow destinations. The results from this study show that there are differences between these two shadow destinations.

There are many similarities between Östersund and Härnösand but there are also a number of differences. Östersund is located further away from the main attraction in the area, Åre, than Härnösand is from the High Coast. Brand extension is active in Östersund with Östersund Airport being renamed Åre/Östersund Airport despite it being located almost $90 \mathrm{~km}$ from Åre. Brand extension is the marketing of a new product as an extension of an existing one. This is a well-known strategy to intensify brand value efficiently (Kim, Misra and Shapiro, 2019). Härnösand can be a good supplement of the brand "The High Coast", especially in the context of events, gastronomy, and nature-based tourism. Since the concept of destination extension has not yet been sufficiently addressed in this field of study, and Härnösand wants to develop its potential in tourism, it could be a positive idea to develop this concept. Härnösand needs to develop products and services that can bring tourists valuable experiences and that draw them to Härnösand. Since 2012/2013 the city has had a stronger collaboration with the whisky distillery, which is a strong brand in this region that has recently changed its name to the High Coast Distillery. This shows the importance of the High Coast brand and how it has been adopted by various companies in the region.

Previous research has shown that tourist routes might be a successful way to encourage tourists to take a detour past shadow destinations. There are many examples of great tourist routes travelling through beautiful countryside or including some sort of gastronomy experience. Both of the cities included in this study could also benefit by using the strong brand they are located close to. Strong 
brands are often a great way to communicate with tourists. In Norway, food experiences for tourists are still relatively unheard of (Vitters $\varnothing$ and Amilien, 2011), while in rural Sweden this area of tourism has been further developed. The Norwegian market is of great importance to both cities included in this study. Härnösand could use gastronomic experiences to attract tourists from Norway since Norwegians are interested in local food products.

Since the UNESCO High Coast World Heritage Site is situated on both the Swedish and Finnish coasts of the Gulf of Bothnia, we suggest that further research into the Finnish side would be in order with the aim of identifying possible prospective bi-lateral cooperation. Currently, it is worth mentioning that Finnish bus tourists come to the Swedish side of the World Heritage Site and Härnösand by ferries travelling between Vaasa in Finland and Umeå in Sweden, but on their return home, only word-of-mouth marketing strengthens the brand. Increasing the amount of Finnish and in particular Norwegian tourists is desirable. Other international markets could include German-speaking countries and the Netherlands. However, before driving expansion into foreign markets, strengthening regional and national tourism is necessary.

\section{Conclusions}

It is difficult for shadow destinations to attract tourists who are mainly interested in other geographical areas (e.g. attractions) in the region. The two cases studied in this paper show how shadow destinations have different problems and possibilities. Härnösand is in the shadow of the UNESCO High Coast World Heritage Site while Östersund is in the shadow of the ski resort Åre. This study concludes that the two studied destinations could develop different aspects to attract more people to their destinations. The High Coast is the main reason for tourists to visit Västernorrland County, with the majority of tourists passing by Härnösand, only stopping at the larger supermarkets or petrol stations. The study shows that Härnösand could create new reasons for tourists to visit, such as tourist routes or gastronomy experiences, thereby using the "pull" effect (Gnoth, 1997). This could also be done by marketing existing attractions such as museums and successful tourism ventures. Since the destination is yet to be successful in attracting tourists, another solution could be to provide attractions or reasons for traveling there that work as a complement to the High Coast. Härnösand could strongly benefit from using the High Coast brand in their tourism development work. Östersund, on the other hand, can work with their own brand and is not as dependent on Åre as a brand. Östersund attracts many tourists due to various events such as music festivals, football tournaments and World Cup Biathlon competitions. A large number of tourists visiting Östersund are Norwegians for the shopping, which is more of a push factor here due to prices being much higher in Norway. We can conclude that the two cases' dependence on the well-known destinations they are located close to differs. One way to encourage tourists to visit shadow destinations is by developing tourist routes or gastronomy experiences or a combination of these two tools. 
This study contributes to this area of knowledge by concluding that there are different types of shadow destinations that depend on the brand as well as the distance from a well-known destination. The practical implications that can be taken from this paper outline how shadow destinations could benefit from a successful brand in their regions and investigate how they can add value for the existing tourists that are in the area.

In conclusion, shadow destinations are highly dependent on high-profile destinations in their region. This means that they can benefit from being in the same geographical area as these destinations despite the shadow they cast. Shadow destinations could add value to tourists in well-established destinations by offering attractions that benefit tourists. Networking between the destinations and the usefulness of the well-known brand in their communication towards the tourists is of importance. Shadow destinations could also help well-known destinations to become more sustainable when the pressure of too many tourists visiting the wellestablished destinations is reduced. Finally, shadow destinations could create different types of tourist routes that make the tourists choose other ways and therefore experience attractions in the shadow destination.

\section{References}

Aaker, D. A. (2010). Brand relevance: Making competitors irrelevant. John Wiley and Sons.

Andersson, T. D., Mossberg, L., \& Therkelsen, A. (2017). Food and tourism synergies: Perspectives on consumption, production and destination development. Scandinavian Journal of Hospitality and Tourism, 17(1), 1-8. DOI = https://doi.org/10.1080/15022 250.2016.1275290.

Andriotis, K. (2005). Community groups' perceptions of and preferences for tourism development: Evidence from Crete. Journal of Hospitality and Tourism Research, 29(1), 67-90. DOI = https://doi.org/10.1177\%2F1096348004268196.

Ashton, A. S. (2014). Tourist destination brand image development —an analysis based on stakeholders' perception: A case study from Southland, New Zealand. Journal of Vacation Marketing, 20(3), 279-292. DOI = https://doi.org/10.1177\%2F1356766713 518061.

Ashworth, G., and Kavaratzis, M. (2009). Beyond the logo: Brand management for cities. Journal of Brand Management, 16(8), 520-531. DOI = https://doi.org/10.1057/palg rave.bm. 2550133 .

Baloglu, S., and Uysal, M. (1996). Market segments of push and pull motivations: A canonical correlation approach. International Journal of Contemporary Hospitality Management, 8(3), 32-38. DOI = https://doi.org/10.1108/09596119610115989.

Birka Cruises AB (2019). https://bit.ly/2OmdQx3 Accessed 2019-05-01.

Bregoli, I., Hingley, M., Del Chiappa, G., and Sodano, V. (2016). Challenges in Italian wine routes: managing stakeholder networks. Qualitative Market Research: An International Journal, 19(2), 204-224. DOI = https://doi.org/10.1108/QMR-02-20160008 .

Briedenhann, J., and Wickens, E. (2004). Tourism routes as a tool for the economic development of rural areas - vibrant hope or impossible dream? Tourism Management, 25(1), 71-79. DOI = https://doi.org/10.1016/S0261-5177(03)00063-3. 
Butler, R. W. (1980). The concept of a tourist area cycle of evolution: implications for management of resources. Canadian Geographer, 24, 5-12.

Byrd, E. T., Bosley, H. E., and Dronberger, M. G. (2009). Comparisons of stakeholder perceptions of tourism impacts in rural eastern North Carolina. Tourism Management, 30(5), 693-703. DOI = https://doi.org/10.1016/j.tourman.2008.10.021.

Camping.se (2019). https://www.camping.se/en/Campingse-International/Destinations/ Routes/Routes-worth-a-detour/ Accessed 2019-06-09.

Dabphet, S., Scott, N., and Ruhanen, L. (2012). Applying diffusion theory to destination stakeholder understanding of sustainable tourism development: A case from Thailand. Journal of Sustainable Tourism, 20(8), 1107-1124.

DOI $=$ https://doi. org/10.1080/09669582.2012.673618.

Ellis, S., and Sheridan, L. (2014). A critical reflection on the role of stakeholders in sustainable tourism development in least-developed countries. Tourism Planning and $\begin{array}{llll}\text { Development, } & 11(4), & \text { 467-471. } & \text { DOI }\end{array}$ https://doi.org/10.1080/21568316.2014.894558.

Fredman, P., and Tyrväinen, L. (2010). Frontiers in nature-based tourism. Scandinavian Journal of Hospitality and Tourism, 10(3), 177-189. DOI = https://doi.org/10.1080/ 15022250.2010 .502365 .

Getz, D., Robinson, R., Andersson, T. D., and Vujicic, S. (2014). Foodies \& food tourism. Oxford: Goodfellow.

Gnoth, J. (1997). Tourism motivation and expectation formation. Annals of Tourism Research, 24(2), 283-304. DOI = https://doi.org/10.1016/S0160-7383(97)80002-3.

Govers, R., and Go, F. (2009). Glocal, virtual and physical identities, constructed, imagined and experienced. Basingstoke: Palgrave Macmillan. DOI $=$ https://doi.org/ 10.1007/978-0-230-24702-4.

Haugland, S. A., Ness, H., Grønseth, B. O., and Aarstad, J. (2011). Development of tourism destinations: An integrated multilevel perspective. Annals of Tourism Research, 38(1), 268-290. DOI = https://doi.org/10.1016/j.annals.2010.08.008.

Härnösand (2019). Härnösands kommun. (Härnösand Municipality). https://www.har nosand.se/kultur--fritid.html Accessed 2019-05-12. https://bit.ly/37FYwmt. Accessed 2019-05-12.

Hudman, L. and Jackson, R. (2003). Geography of Travel and Tourism. Cengage Learning. $4^{\text {th }}$ edition.

Insch, A. (2011). Conceptualization and anatomy of green destination brands. International Journal of Culture, Tourism and Hospitality Research, 5(3), 282-290. DOI = https://doi.org/10.1108/17506181111156970.

Jacobsen, J. Kr. S., Iversen, N. M., and Hem, L. E. (2019). Hotspot crowding and overtourism: Antecedents of destination attractiveness. Annals of Tourism Research, 76(2019), 53-66. DOI = https://doi.org/10.1016/j.annals.2019.02.011.

Jämtland Härjedalen Turism. (2018). https://bit.ly/34vzS6o Accessed 2019-05-05.

Järvensivu, T., and Törnroos, J. А. (2010). Case study research with moderate constructionism: Conceptualization and practical illustration. Industrial Marketing Management, 39(1), 100-108. DOI = https://doi.org/10.1016/j.indmarman.2008.05. 005 .

Keller, K. L. (2016). Reflections on customer-based brand equity: perspectives, progress, and priorities. AMS review, 6(1-2), 1-16. https://doi.org/10.1007/s13162-016-0078-z

Kim, Y., Misra, S., and Shapiro, B. (2019). Value Brand Collaboration: Evidence From a Natural Experiment. University of Chicago. DOI = https://doi.org/10.2139/ssrn.333 5833. 
Kivela, J., and Crotts, J. C. (2005). Gastronomy tourism. A meaningful travel market segment. Journal of Culinary Science and Technology, 4 (2-3), 39-55. DOI = https:// doi.org/10.1300/J385v04n02_03.

Kladou, S., Kavaratzis, M., Rigopoulou, I., and Salonika, E. (2017). The role of brand elements in destination branding. Journal of Destination Marketing and Management, 6(4), 426-435. DOI = https://doi.org/10.1016/j.jdmm.2016.06.011.

Kliem, T. (2003). Reisemotive, Reiseverhalten und Wahrnehmungen deutscher Touristen in Norwegen als Grundlage der Entwicklung neuer Konzepte für die norwegische Tourismuswirtschaft. (Travel motives, travel behaviour and perceptions of German tourists in Norway as a basis for the development of new concepts for the Norwegian tourism industry). Approved Dissertation by the Faculty of Social Sciences at University Duisburg-Essen. https://bit.ly/2KXtQ6q Accessed 2019-04-12.

Leimgruber, W. (2017). Tourism in the Swiss Alps: The Human Factor in Local Development. In Societies, Social Inequalities and Marginalization (273-287): Springer. DOI = https://doi.org/10.1007/978-3-319-50998-3_17.

Leiper, N. (1990). Tourism systems: An interdisciplinary perspective. Department of Management Systems, Business Studies Faculty, Massey University.

Lourens, M. (2007). Route tourism: a roadmap for successful destinations and local economic development. Development Southern Africa, 24(3), 475-490. DOI = https:// doi.org/10.1080/03768350701445574.

Lundberg, C., and Fredman, P. (2012). Success factors and constraints among naturebased tourism entrepreneurs. Current Issues in Tourism, 15(7), 649-671. DOI = https://doi. org/10.1080/13683500.2011.630458.

Meyer, D. (2004). Tourism routes and gateways: Key issues for the development of tourism routes and gateways and their potential for pro-poor tourism. ODI discussion paper. https://bit.ly/2Dn8v2o Accessed 2019-04-30.

Mundt, J. W. (2012). Tourismus. (Tourism). 4. überarbeitete und ergänzte Auflage. (4 $4^{\text {th }}$ and renewed edition). De Gruyter Oldenbourg. ISBN 9783486704518.

Östersund (2019). Östersunds kommun. (Östersund Municipality). https://bit.ly/2ONc8E7 Accessed 2019-05-01. https://bit.ly/2DjIy3N Accessed 2019-05-01.

Pikkemaat, B. (2012). Von der Idee zur Innovation. Ein praktischer Wegweiser für touristische Unternehmen (From the idea to the innovation. A practical guide for touristic firms). https://bit.ly/2ONc9Ib Accessed 2019-04-10.

Prideaux, B. (2000). The role of the transport system in destination development. Tourism management, 21(1), 53-63. DOI = https://doi.org/10.1016/S0261-5177(99)00079-5

$\mathrm{Qu}, \mathrm{H} ., \mathrm{Kim}, \mathrm{L}$. H., and Im, H. H. (2011). A model of destination branding: Integrating the concepts of the branding and destination image. Tourism Management, 32(3), 465476. DOI = https://doi.org/10.1016/j.tourman.2010.03.014.

Saarinen J., Rogerson, C. \& Hall, M. (2017) Geographies of tourism development and planning, Tourism Geographies, 19(3), 307-317. DOI = https://doi.org/10.1080/461 6688.2017.1307442

Sánchez Cañizares, S. M., Castillo Canalejo, A. M., and Núñez Tabales, J. M. (2016). Stakeholders' perceptions of tourism development in Cape Verde, Africa. Current Issues in Tourism, 19(10), 966-980. DOI = https://doi.org/10.1080/13683500.2015. 1008428.

Shen, Y., Morrison, A. M., Wu, B., Park, J., Li, C., and Li, M. (2018). Where in the World? A Geographic Analysis of a Decade of Research in Tourism, Hospitality, and Leisure Journals. Journal of Hospitality \& Tourism Research, 42(2), 171-200. DOI = http://doi.org/10.1177/1096348014563394. 
Sims, R. (2009). Food, place and authenticity: local food and the sustainable tourism experience. Journal of Sustainable Tourism, 17(3), 321-336. DOI $=10.1080 / 096695$ 80802359293.

Skärgårdsvägen (2019). (Archipelago route). http://skargardsvagen.se/english Accessed 2019-05-02. https://sv-se.facebook.com/skargardsvagen Accessed 2019-05-02.

Sörensson, A., Dalborg, C., and Bogren, M. (2016). National branding: What role does food play? In Valuing and Evaluating Creativity for Sustainable Regional Development (38-38). ISBN: 978-91-88527-26-4. https://bit.ly/33roA1o Accessed 2019-04-14.

Snilleriket (2019). (The kingdom of geniuses). http://snilleriket.se/ Accessed 2019-05-02. https://www.facebook.com/Snilleriket/ Accessed 2019-05-02.

Statistiska Centralbyrån (Statistics in Sweden). (2019). https://www.scb.se/en/ Accessed 2019-05-03.

Tasci, A. D., and Ko, Y. J. (2017). Travel needs revisited. Journal of Vacation Marketing, 23(1), 20-36. DOI = https://doi.org/10.1177\%2F1356766715617499.

The High Coast (2019). https://www.hogakusten.com/en/cities-places/harnosand Accessed 2019-05-13.

United Nations Educational, Scientific and Organizational Education (UNESCO). (2017). https://bit.ly/2slLXwE Accessed 2019-05-05.

United Nations Educational, Scientific and Organizational Education (UNESCO). (2019). http://creativegastronomy.com/ccn/gastronomy-cities Accessed 2019-05-01.

Visit Östersund AB (2019). Matupplevelser Östersund. (Food experiences Östersund). https://visitostersund.se/matupplevelser Accessed 2019-04-30.

VisitSweden (2019). Måltidsturism. (Gastronomy Tourism). Presented by Frida Wallén at the Eldrimner Conference in Ås, Sweden on 2 October 2018.

Vitters $\emptyset$, G., and Amilien, V. (2011). From tourist product to ordinary food? The role of rural tourism in development of local food and food heritage in Norway. Anthropology of food (8). https://journals.openedition.org/aof/6833 Accessed 2019-04-20.

White Guide. (2019). Sveriges bästa restauranger och caféer. (Sweden's best restaurants and cafés). https://bit.ly/34pWm8I Accessed 2019-05-01.

Witt, C. A., and Wright, P. L. (1992). Tourist motivation: life after Maslow. 33-35. ISBN: 072-01-21183. 
